\title{
Group Contribution Method to Estimate the Biodegradability of Organic Compounds
}

Jhamb, Spardha; Hospital, Irene; Liang, Xiaodong; Pilloud, Francis; Piccione, Patrick M.; Kontogeorgis, Georgios M.

Published in:

Industrial and Engineering Chemistry Research

Link to article, DOI:

10.1021/acs.iecr.0c03759

Publication date:

2020

Document Version

Peer reviewed version

Link back to DTU Orbit

Citation (APA):

Jhamb, S., Hospital, I., Liang, X., Pilloud, F., Piccione, P. M., \& Kontogeorgis, G. M. (2020). Group Contribution Method to Estimate the Biodegradability of Organic Compounds. Industrial and Engineering Chemistry

Research, 59(47), 20916-20928. https://doi.org/10.1021/acs.iecr.0c03759

\section{General rights}

Copyright and moral rights for the publications made accessible in the public portal are retained by the authors and/or other copyright owners and it is a condition of accessing publications that users recognise and abide by the legal requirements associated with these rights.

- Users may download and print one copy of any publication from the public portal for the purpose of private study or research.

- You may not further distribute the material or use it for any profit-making activity or commercial gain

- You may freely distribute the URL identifying the publication in the public portal 


\section{A Group Contribution Method to Estimate the}

\section{Biodegradability of Organic Compounds}

Spardha Jhamb ${ }^{a}$, Irène Hospital ${ }^{a}$, Xiaodong Liang ${ }^{a}$, Francis Pilloud ${ }^{b}$, Patrick M. Piccione ${ }^{c, d}$, Georgios M. Kontogeorgis ${ }^{a^{*}}$

${ }^{a}$ Department of Chemical and Biochemical Engineering, Technical University of Denmark, Building 229, Søltofts Plads 229, DK - 2800, Kgs. Lyngby, Denmark.

${ }^{b}$ Syngenta Crop Protection SA, Route de l'Ile au Bois, 1870 Monthey, Switzerland 'Syngenta, Breitenloh 5, CH 4333, Münchwilen, Switzerland

${ }^{d}$ Current address: F. Hoffmann-La Roche AG, Grenzacherstrasse 124, 4070 Basel, Switzerland

*Correspondence to Georgios M. Kontogeorgis,

KT Consortium, Department of Chemical and Biochemical Engineering, Technical University of Denmark, Building 229, Søltofts Plads 229, DK - 2800, Kgs. Lyngby, Denmark.

Email: gk@kt.dtu.dk; Telephone: +45 452528 59; Fax: +45 45882258 


\section{ABSTRACT}

The study of biodegradation of chemicals that are discharged into the water bodies is important to determine the risk to the environment that is associated with the chemical. The biodegradability of a chemical can be characterised by conventional oxidation parameters such as biochemical oxygen demand (BOD), chemical oxygen demand (COD) and theoretical oxygen demand (ThOD).

Since the $\mathrm{BOD}_{5}$ estimation method takes five days, other methods have been sought for measuring oxygen requirements of a sample. One of them is the chemical oxygen demand (COD) test which makes use of a strong oxidising agent under acidic conditions.

In this paper a combination of $\mathrm{BOD}_{5}$ and $\mathrm{COD}$ experimental data is used to develop a quantitative model for the prediction of biodegradability. Furthermore, the criterion used to classify a substance as 'readily biodegradable' is the one specified by the European Chemical Agency (EChA)'s CLP (Classification, Labelling and Packaging) Regulation.

KEYWORDS: Biodegradation, Biochemical Oxygen Demand (BOD), Chemical Oxygen Demand (COD), European Chemical Agency (EChA) CLP (Classification, Labelling and Packaging) Regulation, Group Contribution Model 


\section{Introduction}

\subsection{Defining Biodegradation}

Biodegradation is a complex process consisting of many steps that critically depend on chemical structure, environmental conditions into which a chemical is released and the bioavailability of the chemical. Qualitatively, biodegradation is defined as the ability of living organisms to reduce or eliminate environmental hazards resulting from accumulations of toxic chemicals and other hazardous wastes ${ }^{1}$.

In biological terms, this implies the breakdown of organic matter by micro-organisms e.g. bacteria and fungi, which use the organic matter as nutrients and decompose it into non-hazardous components: water, carbon dioxide and other minerals as per the following equation ${ }^{1}$,

Under aerobic conditions:

organic substrate $+\mathrm{O}_{2} \rightarrow$ biomass $+\mathrm{CO}_{2}+\mathrm{H}_{2} \mathrm{O}+$ residue

Under anaerobic conditions:

Some microorganisms obtain energy from fermentation and anaerobic oxidation of organic carbon. Many anaerobic organisms (anaerobes) use nitrate, sulfate, and salts of iron (III) as practical alternatives to oxygen acceptor. For example, in the anaerobic reduction process of nitrates, sulfates, and salts of iron (III) the following reactions take place:

$2 \mathrm{NO}_{3}{ }^{-}+10 \mathrm{e}^{-}+12 \mathrm{H}^{+} \rightarrow \mathrm{N}_{2}+6 \mathrm{H}_{2} \mathrm{O}$
$\mathrm{SO}_{4}{ }^{2-}+8 \mathrm{e}^{-}+10 \mathrm{H}^{+} \rightarrow \mathrm{H}_{2} \mathrm{~S}+4 \mathrm{H}_{2} \mathrm{O}$
$\mathrm{Fe}(\mathrm{OH})_{3}+\mathrm{e}^{-}+3 \mathrm{H}^{+} \rightarrow \mathrm{Fe}^{2+}+3 \mathrm{H}_{2} \mathrm{O}$ 
Briefly, biodegradation involves different stages. First, bio-deterioration occurs wherein, a change of mechanical, chemical and physical properties of the material takes place. The structure is weakened by external abiotic factors such as compression, light and temperature. Next, biofragmentation occurs wherein, the polymers bonds cleave. This is highly regulated by the presence of oxygen. Lastly, assimilation occurs wherein the products of biodegradation are integrated into microbial cells.

Biodegradation can happen under different environmental conditions that can enhance or reduce its rate. Important factors for its success are:

- The presence of metabolically capable micro-organisms

- A suitable environment (as the presence of oxygen)

- A temperature between 10 and 35 degrees: keeping a substance frozen or below the optimal operating temperature for microbial species, can prevent biodegradation

- The presence of water

- An appropriate level of nutrients and contaminants

- A favorable $\mathrm{pH}$ and alkalinity as microbial species that degrade the different compounds survive in a specific $\mathrm{pH}$ range. The optimum $\mathrm{pH}$ for hydrocarbons degradation is 7 and a globally suitable one is between 6 and 8

In this work, only the case of aerobic condition is used due to the availability of sufficient data for developing a quantitative model to predict the biodegradability of organic compounds. Therefore, from this point further, the term 'biodegradation' implies 'aerobic biodegradation'. 


\section{Quantifying Biodegradability}

Biodegradability is a difficult property to model owing to the complexity of the biodegradation phenomenon as described above. Specifically, the biodegradability of a chemical can be quantitatively estimated by conventional oxidation parameters for bio-degradation according to the Organization for Economic Cooperation (OECD) report ${ }^{2}$.

Biochemical Oxygen Demand (BOD): Biochemical oxygen demand (mg) is the amount of oxygen consumed by micro-organisms when metabolizing a test compound.

Chemical Oxygen Demand (COD): Chemical oxygen demand (mg) is the amount of oxygen consumed during oxidation of a test compound with hot, acidic dichromate. It provides a measure of the amount of oxidizable matter present.

Theoretical Oxygen Demand (ThOD): Theoretical oxygen demand (mg) is the total amount of oxygen required to oxidize a chemical completely. It is calculated using stoichiometry and is also expressed.

Total Organic Carbon (TOC): Total organic carbon of a sample is the sum of the organic carbon in solution and in suspension.

The BOD, COD and ThOD are all expressed as mg oxygen uptake per mg test compound. The TOC on the other hand is expressed as mg organic carbon per L test solution.

It is possible to determine whether a particular compound is biodegradable or not, using the oxidation numbers described above. Different criteria are used in literature regarding these numbers. The most used one is the oxidation number BOD5, which represents the BOD calculated during 5 days of incubation of a sample containing the compound at 20 degree Celsius in the dark. 
This involves calculating the consumed oxygen during that period to estimate the biodegradability of the sample. However, five days are rarely enough to reach a complete biodegradation expressed by the 'ultimate biochemical oxygen demand: $\mathrm{BODu}$ '. The $\mathrm{BOD}_{5}$, therefore represents only around 77 percent of the complete reaction.

According to the European Chemical Agency (EChA)'s CLP (Classification, Labelling and Packaging) Regulation in connection with degradation, a substance is considered to be rapidly biodegradable in the environment if one of the following three criteria are satisfied ${ }^{3}$ :

(a) Readily biodegradable in biodegradation screening test

(b) Ratio of the five-day biochemical oxygen demand (BODs) to chemical oxygen demand (COD): $\mathrm{BOD}_{5} / \mathrm{COD}>=0.5$

(c) Other convincing scientific evidence that the substance can be degraded in the aquatic environment to a level $>70$ percent within a 28 -day period; for instance, if the $\mathrm{BOD}_{28}$ is greater than 70 percent of the ThOD, then the substance is considered to be readily biodegradable

A more complete way to define the range of biodegradability ${ }^{4,5}$ is as follows:

BOD $5 / \mathrm{COD}>0.5$ : easily biodegradable

$\mathrm{BOD} 5 / \mathrm{COD}=0.4-0.5:$ middle

$\mathrm{BOD}_{5} / \mathrm{COD}=0.2-0.5$ : slowly biodegradable

BOD $5 / C O D<0.2$ : not biodegradable

Apart from the EU regulations, there are some other regulations to estimate the pollution of effluents according to different locations. These are briefly summarized below ${ }^{6}$ : 
- In Asia, $\mathrm{BOD}_{5}$ value is directly used: between $5-15 \mathrm{mg} / \mathrm{L}$ means moderately polluted and a $\mathrm{BOD}_{s}$ above $15 \mathrm{mg} / \mathrm{L}$ leads to severely polluted environment.

- In France, a $\mathrm{BOD}_{5}<100 \mathrm{mg} / \mathrm{L}$ and a COD $<300 \mathrm{mg} / \mathrm{L}$ are limited for effluent open waterways.

- In Germany, the COD needs to be inferior to 4 times the TOC to define the environment as acceptable.

However, the oxidation parameter TOC has recently come into attention as its experimental value can be obtained much faster. Correlations between the TOC, $\mathrm{COD}$ and $\mathrm{BOD}_{5}$ parameters have been established so the use of TOC could accelerate the establishment of biodegradation.

\subsection{Models for Prediction of Biodegradability}

\subsubsection{Quantitative Structure-Activity Relationship Models}

\section{Chemical descriptor based}

Grammatica et al. ${ }^{7}$ proposed models to quantify the biodegradability of a chemical based on theoretical descriptors, where a genetic algorithm (GA) was used as the variable subset selections technique to search for the most relevant molecular descriptors. A diverse data set consisting of 71 alcohols, ketones and aromatic compounds, 15 anilines and phenols, 17 polychlorinated biphenyls and 43 heterogeneous compounds with BOD and percent of theoretical oxygen demand (TOD) data from the literature was used.

Each descriptor present in the compounds is denoted by an information bit equal to one if it is present in the regression model and equal to zero if it is absent from the model. A population constituted of zero/one strings is evolved by the GA. The developed regression models for BOD and $\%$ ThOD had a satisfactory performance $\left(\mathrm{R}^{2}=82-84 \% \text { and } \mathrm{Q}^{2}=78-82 \%\right)^{8}$.

\section{Fragment based (Group Contribution)}


The US-EPA (Environmental Protection Agency) has already developed seven group contribution models for assessing the biodegradability of a compound ${ }^{9}$. They have developed different mathematical models: Four models that predict the probability of biodegradation, two models that predict the time needed for a compound to achieve an either primary or ultimate biodegradation and one model based on anaerobic biodegradation. All these seven models are available via the software - EPI Suite ${ }^{10}$, which can be downloaded freely from the US-EPA website and they are briefly described below:

a) BIOWIN1 and BIOWIN2: These two models predict the probability of biodegradation using experimental values from the BIODEG database (National Information Services Corporation (NISC) U.S., 2000). A probability value of greater than 0.5 indicates that the compound is rapidly biodegradable. The development of these models makes use of 295 chemicals in the database and a linear and nonlinear regression is performed to estimate the parameters for BIOWIN1 and BIOWIN2 respectively.

For carrying out the regression, every compound in the set studied was defined as 'rapidly biodegradable' or 'not rapidly biodegradable' based on the experimental evaluation of biochemical oxygen demand (BOD), $\mathrm{CO}_{2}$ production, loss of parent molecule properties etc. Then, depending on whether they were rapidly biodegradable, an indicator variable was assigned the value of 1 or 0 respectively.

Using 37 independent variables namely the frequency of structural fragments, $f_{i}$ (number of times a substructure occurs in a molecule) and the molecular weight, $M_{w}$, the models to predict the probability for chemical $j$ to biodegrade, $Y_{j}$ are developed.

- The linear model is given by the following equation: 
$Y_{j}=a_{0}+a_{1} f_{1}+a_{2} f_{2}+\cdots+a_{36} f_{36}+a_{m} M_{w}+e_{i}$

- The non-linear model is expressed as follows:

$Y_{j}=\frac{\exp \left(a_{0}+a_{1} f_{1}+a_{2} f_{2}+\cdots+a_{36} f_{36}+a_{m} M_{w}+e_{j}\right)}{1+a_{0}+a_{1} f_{1}+a_{2} f_{2}+\cdots+a_{36} f_{36}+a_{m} M_{w}+e_{j}}$

where,

- $a_{i}=$ regression coefficient

- $e_{j}=$ error term

- $a_{m}=$ regression coefficient of the molecular weight

- $M_{w}=$ molecular weight

b) BIOWIN3 and BIOWIN4: These two models predict the time frame for primary and ultimate biodegradation respectively. They are based on a survey conducted by a panel of 17 experts.

They studied the tendency of compounds to biodegrade by defining score numbers in terms of scale of reaction time: $5=$ hours; $4=$ days; $3=$ weeks; $2=$ months; $1=$ longer. Then, an arithmetic mean was applied on these values reported by different scientists for each compound.

c) BIOWIN5 and BIOWIN6: Like BIOWIN1 and BIOWIN2, these models also predict the probability of biodegradation. However, the development of them made use of 884 compounds from the Japanese MITI (Ministry of International Trade and Industry) database.

The experimental data for these compounds is based on respirometry analytical methods which measures oxygen consumption. This test assigned the property of being readily biodegradable if the $\mathrm{BOD}_{28}>=60 \%$ ThOD. This does not take into account the COD parameter. Also, the group contribution models used are based on 42 fragments instead of 36 . 
d) BIOWIN7: This is a screening-level model for the prediction of anaerobic ultimate biodegradation in sludge digesters. It was developed from a data set of 169 chemicals tested for methanogenic anaerobic biodegradation using the serum bottle method. There are controversies on the validity of aerobic models for anaerobic conditions ${ }^{2}$. Regarding the molecular fragments used in BIOWIN models, the same coefficient for the different models were found. However, there are other rules which apply to anaerobic conditions specifically as unsaturated (olefenic) hydrocarbons degrade much faster than saturated hydrocarbons ${ }^{2}$.

It is worth noticing that the ratio used by BIOWIN5 and BIOWIN6 of $\mathrm{BOD}_{28}>=60 \% \mathrm{TOD}$ is one of the possible parameters to define a compound as readily biodegradable. Many others, as Dissolved Oxygen Content (DOC) and $\mathrm{CO}_{2}$ production can also be used ${ }^{11}$.

Their method has different advantages: even though it lacks precision, it still provides quantitative or semi-quantitative estimates of biodegradation rate for use in chemical ranking schemes and also estimates the probability of rapid biodegradation. Still, the fragment constant approach to biodegradability modeling is simplistic and does not, for example, take into account the possible interactions among fragments in multifunctional molecules. Moreover, the sum of the coefficients of the regressed equations have low reliability as the number of compounds used to estimate them are very few. For example, very few compounds which contain the aromatic F, N-nitroso and aliphatic Br fragments are used in the regression. The ProCAMD tool in $\operatorname{ICAS}^{12}$ enables the user to make use of some of the above biodegradation models (BIOWIN1 - BIOWIN4). The performance of these models is satisfactory with a $\mathrm{R}^{2} \approx 0.7$.

\subsubsection{Inductive Machine Learning Models}

Artificial intelligence techniques to model biodegradability were presented by Gamberger et al. ${ }^{13}$ and Gamberger et al. ${ }^{14}$. They derived rules using inductive machine learning methods based on 
structural requirements in order to predict slow and fast biodegradation. A total of 341 compounds comprising of 293 substances from the BIODEG database and a set of expert judgements for 48 chemicals is used as the dataset to develop the three simple structure-based rules. This makes use of an example-based learning system.

The model was able to correctly classify $80 \%$ of readily biodegradable predictions and $90 \%$ of not readily biodegradable predictions. The defined rules are based on combinations of structural groups that allow neighboring structures to be considered.

\section{Development of a Group Contribution Model to Predict Biodegradability}

The group contribution models are an efficient method for property prediction due to their simplicity and computational efficiency. Although, the US-EPA has developed seven group contribution models for biodegradability prediction, they do not cover an exhaustive range of organic compounds due to the small number of molecular descriptors used. Therefore, in this work, a GC model that can be used for a more comprehensive range of compounds, is developed.

\subsection{Methods and Tools Used for Model Development}

A systematic methodology based on the property-data-model-analysis is used ${ }^{15}$ to develop a GCmodel. The methodology includes three steps. First, a trend analysis of the property values (obtained through a literature review or by conducting experiments) is performed for various classes of compounds as a function of their molecular weight. Second, the most appropriate form of the property model equation, $f(x)$, based on the observed trends is selected. Lastly, parameter regression using all the available datapoints in order to obtain model parameter values (group contributions), is performed. This in turn can be used to predict the values of the physical property. 
After the model has been developed, an analysis of prediction errors (that is, the difference between the experimental value and the predicted value) for all compounds in the dataset is made. The model performance is evaluated by the statistical parameters such as coefficient of determination $\left(\mathrm{R}^{2}\right)$, standard deviation (SD), average absolute error (AAE) and average relative error (ARE). If the calculated model performance statistics are acceptable, then the estimated GC-model parameters are considered as final. Otherwise, the steps in the procedure described is repeated until the desired correlation statistics are achieved.

While developing property models, very often, the experimental dataset is divided into training and validation sets. However, while developing a GC-model, it is better to use all the available experimental datapoints in the parameter estimation step as it results in lower uncertainties of estimated model parameters and hence lower uncertainties (better reliability) of the predicted property values ${ }^{15}$. The difference in the change in predictivity of the model on including the validation dataset for parameter estimation, has been highlighted in this work.

\subsubsection{The Marrero and Gani (MG) Method}

In the MG GC-method, the property estimation is performed at three levels. The first level has a large set of simple and monofunctional groups that represent the complete organic compound. The second level of estimation involves polyfunctional, polar/nonpolar compounds of medium size (C = 3-6); aromatic or cycloaliphatic compounds with only one ring and several substituent groups that provide better description of proximity effects and can differentiate among isomers. The third level of estimation includes groups that provide more structural information for molecular fragments of compounds, whose description is insufficient through the first and second level groups.

The MG GC-model has the form ${ }^{16}$, 
$f(X)=\sum_{i} N_{i} C_{i}+w \sum_{j} M_{j} D_{j}+z \sum_{k} O_{k} E_{k}$

The function $f(X)$ is a function of property $X$ and it may contain additional adjustable model parameters (universal constants) depending on the property involved. In Eq. (7), $C_{i}$ is the contribution of the first-order group of type- $i$ that occurs $N_{i}$ times. $D_{j}$ is the contribution of the second-order group of type- $j$ that occurs $M_{j}$ times. $E_{k}$ is the contribution of the third-order group of type- $k$ that has $O_{k}$ occurrences in a component. Eq. (7) is a general model applicable to all properties and the definition of $f(X)$ is specific for each property $X$.

An example showing the molecular structure representation of the compound: $\mathrm{N}-[(2-$ Hydroxyphenyl)methyl]-4-phenylbenzamide using first-order, second-order and third-order groups of the MG GC-method is given in Table 1.

Table 1. Molecular structure representation of N-[(2-Hydroxyphenyl)methyl]-4-phenylbenzamide using the Marrero-Gani (MG) groups

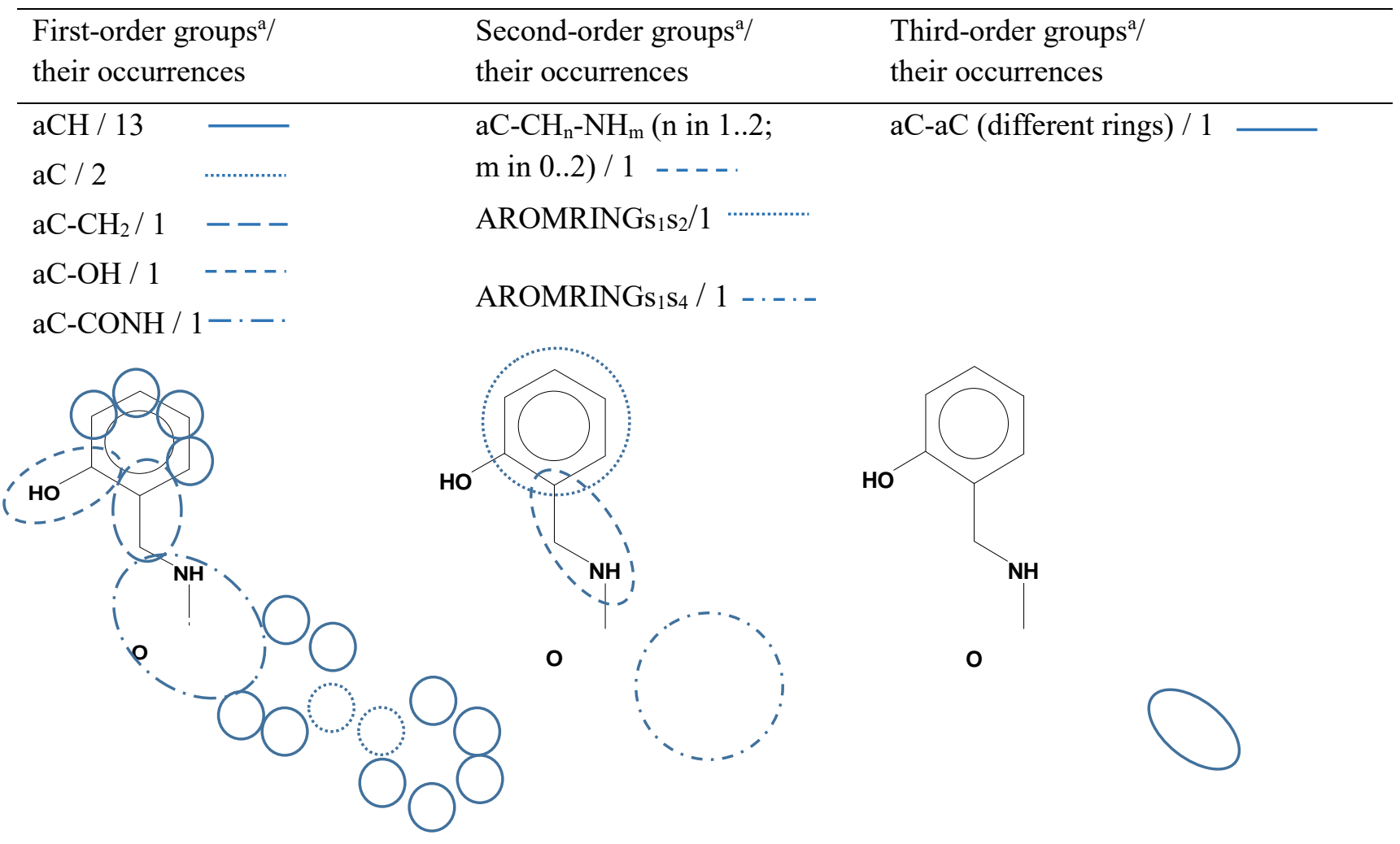


${ }^{a}$ The marked circles in the drawing of the structure of N-[(2-Hydroxyphenyl)methyl]-4-phenylbenzamide show the listed groups in respective symbols.

\subsubsection{Data Sets}

Based on EChA's second criterion of biodegradability, the need for a model to predict the ratio of the oxidation indicators, BOD5 and COD, is recognized. In order to develop a GC model for this, experimental data to estimate the parameters of the model, is required. In this study, the BOD5 and COD values for organic compounds measured in $\mathrm{mg} \mathrm{O}_{2} \cdot \mathrm{L}^{-1}$ were collected. These are compiled as four databases (Database 1 - Database 4) explained below.

\section{Database 1: Simple Acyclic Compounds and Aromatics}

BOD5 and COD experimental data to estimate the parameters of the model for simple acyclic compounds and aromatics were collected. The data is collected from various handbooks and scientific publications ${ }^{17-20}$ containing environmental data. This database is available in the Supporting Information (Table S1).

\section{Database 2: Benzene Ring - Containing Aromatics}

The second database comes from the work of Cvetnic et al. ${ }^{21}$ about the prediction of biodegradability of aromatics in water using QSAR modeling. It makes use of experimental values, obtained from colorimetric method using HACH DR2800 spectrophotometer. Also, its particularity is that it is focused on aromatics containing a benzene ring. This type of structure is the most widespread chemical structure in nature. Therefore, the number, type and position of its substituents are analyzed. Here, 36 single benzene rings compounds are part of the study.

Their biodegradability as the ratio $\mathrm{BOD} 5 / \mathrm{COD}$ has been calculated and then, a $\mathrm{UV}-\mathrm{C} / \mathrm{H}_{2} \mathrm{O}_{2}$ treatment has been conducted on these compounds. As a response, the half-life of parent pollutant has been measured each time. It is worth noting that this definition has never been previously 
mentioned in the literature survey, but this value could be used to analyze the trend of biodegradability of this specific type of compound. The experimental conditions for these different ratios were a temperature of $25+/-0.2{ }^{\circ} \mathrm{C}$ and a time of treatment from 8 to $75.5 \mathrm{~min}$ (corresponding to reaching of half-life $(t / 2)$ for each molecule) with their model solutions $\left(\mathrm{c}_{0}=1\right.$ $\mathrm{mM}$ and $\mathrm{V}=1.4 \mathrm{~L})$.

The database consisting of these compounds is available in Supporting Information (Table S2).

\section{Database 3: Acyclic Compounds, Aromatics and Complex Pesticides}

This database comes from a scientific publication ${ }^{22}$ which is partly an extract from the "ecoinvent" database (starting from the $45^{\text {th }}$ compound) and partly comes from their "in house" analysis which was made to develop molecular structure-based models of chemical inventories using neural networks. The "ecoinvent" database is a Swiss organization which gathers information on thousands of compounds since 2003. This information is used by companies to make more rational environmental choices.

In this database, (database - 3) ten herbicides/pesticides are present. These compounds contain complex chemical formulas and are important compounds in the analysis of biodegradability as they are directly incorporated in the soils. For example, atrazine which is an herbicide widely used in the United States and Australia, was banned in Europe in 2003 for its toxicity ${ }^{23}$.

This database also includes compounds part of BTEX which is a term used in the petrochemical industry and petroleum refining to describe mixtures of benzene, toluene, and the three xylene isomers, all of which are aromatic hydrocarbons. Those compounds are widely used in the industry and can be very toxic to the environment. Their analysis is, with thus essential, to deal current environmental issues. 
This database also contains two compounds containing fluorine, which was not present in the previous database. Also, there are seven amine compounds, which are compounds widely analyzed for their biodegradability as they are considered to be much less degradable than amides. This database is available in Supporting Information (Table S3).

\section{Database 4: Deicers}

This database comes from the work by Corsi, Mericas \& Bowman $^{24}$ and is available in Supporting Information (Table S4). This study is about the oxygen demand of aircraft and airfield pavement deicers and alternative freezing point depressants. Here, BOD5 and COD values are given and thus the ratio has been calculated for each compound.

Globally, it was found that ethylene glycol-based products had lower degradation rates than propylene glycol-based products and that acetate-based products had greater percentage degradation than glycols.

\section{Database 5: Database from Syngenta $A G$}

This database comprises of 45 compounds with $\mathrm{BOD}_{5}$ and COD values measured by Syngenta AG. The compounds in this database are complex agrochemicals. Initially, this database is used only as the validation set for the developed model. However, at a later stage, it is also used as a training set for the model.

\subsubsection{Selection of Suitable Property Model Function}

An appropriate function $\mathrm{f}(\mathrm{X})$ for the ratio of the two oxidation parameters which is modelled in this work was chosen by studying the behaviour of the experimental values for organic compounds with the increasing number of carbon atoms for each class / family of compounds. The ThOD shows an increasing trend with the increase in carbon number as seen from Figure 1. 


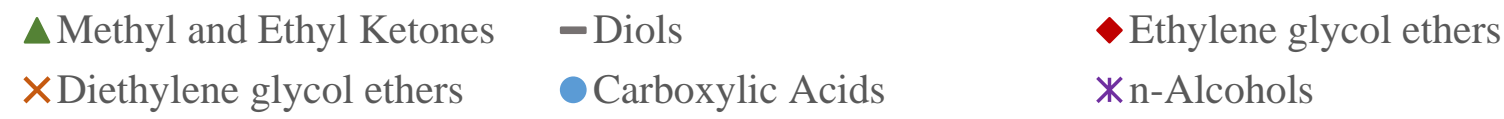

+ Aromatic alcohols

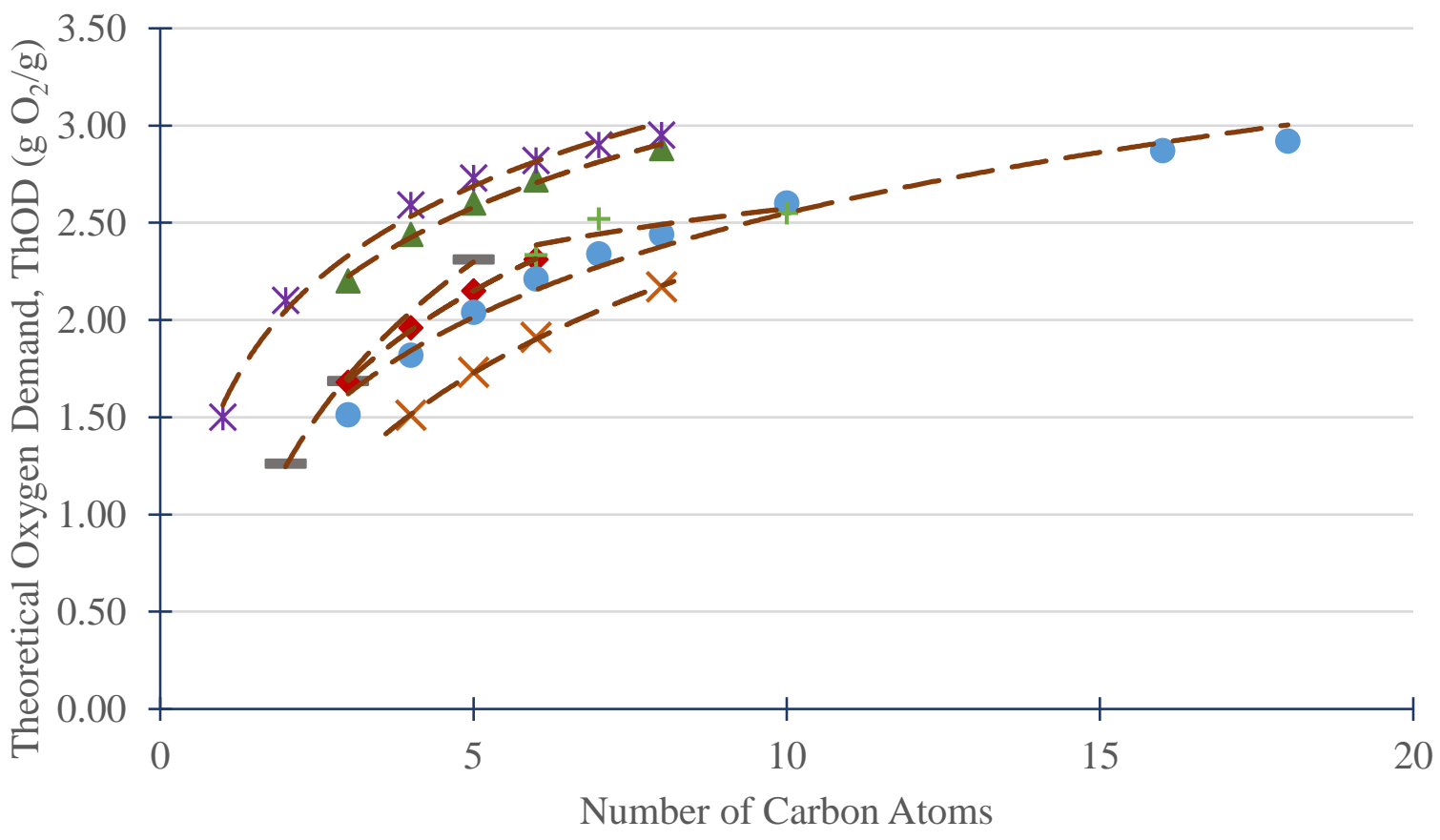

Figure 1. Trend of ThOD with increasing Number of Carbon Atoms

This trend is expected and can be calculated from stoichiometry. As an example, the complete oxidation of primary alcohols is considered. This is given by the equation shown below,

$\mathrm{C}_{n} \mathrm{H}_{2 n+2} \mathrm{O}+\left(n+\frac{n+1}{2}-\frac{1}{2}\right) \mathrm{O}_{2} \longrightarrow n \mathrm{CO}_{2}+(n+1) \mathrm{H}_{2} \mathrm{O}$

After full combustion one mole of this alcohol will generate $n$ mole $\mathrm{CO}_{2}$ and $(n+1)$ mole $\mathrm{H}_{2} \mathrm{O}$. In total, one requires $n$ and $(n+1) / 2$ mole $\mathrm{O}_{2}$ to make these products, respectively. The oxygen atom of the alcohol means that we have $0.5 \mathrm{O}_{2}$ to start with. So, the total oxygen required for the full combustion is $1.5 n$ mole. 
Therefore, ThOD $=$ mass $\mathrm{O}_{2} /$ mass alcohol

$$
\begin{aligned}
& =1.5 n * 32 /(12 n+2 n+2+16) \\
& =24 n /(7 n+9)
\end{aligned}
$$

This function has an asymptotic limit of 24/7 3.4, which is in line with Figure 1. From the entire dataset, it was possible only to identify seven families and classify the data accordingly. Apart from the trend analysis of the ratio of $\mathrm{BOD}_{5}$ to $\mathrm{COD}$, for which the model is developed, the trend analysis for $\mathrm{BOD}_{5}$ and $\mathrm{COD}$ has been individually carried out as well, in order to determine if their trend is similar to that of ThOD, which is calculated from the stoichiometry of an oxidation reaction. However, a monotonic trend is not followed by the individual oxidation parameters, $\mathrm{BOD}_{5}$ and $\mathrm{COD}$ (Figure 2 - Figure 3 ) as well as for the ratio of these oxidation parameters (Figure 4). It has been reported that, in the case of n-alkanes, the ones with longer chains have low solubility and consequently low bioavailability compared to the mid-sized midsized n-alkanes. Moreover, although short-chain n-alkanes have higher aqueous solubility, they are toxic to microbes or cells, and the mechanisms of this toxicity are associated with their uptake and dissolution in the cell membrane ${ }^{25}$. Thus, though short chain n-alkanes are more bioavailable than mid-sized or long chain n-alkanes, they are associated with cell toxicity and hence inhibition of microbial growth resulting in lower BOD values. This explains the observed trend in the property with increase in the chain length for other classes of organic compounds as well. 


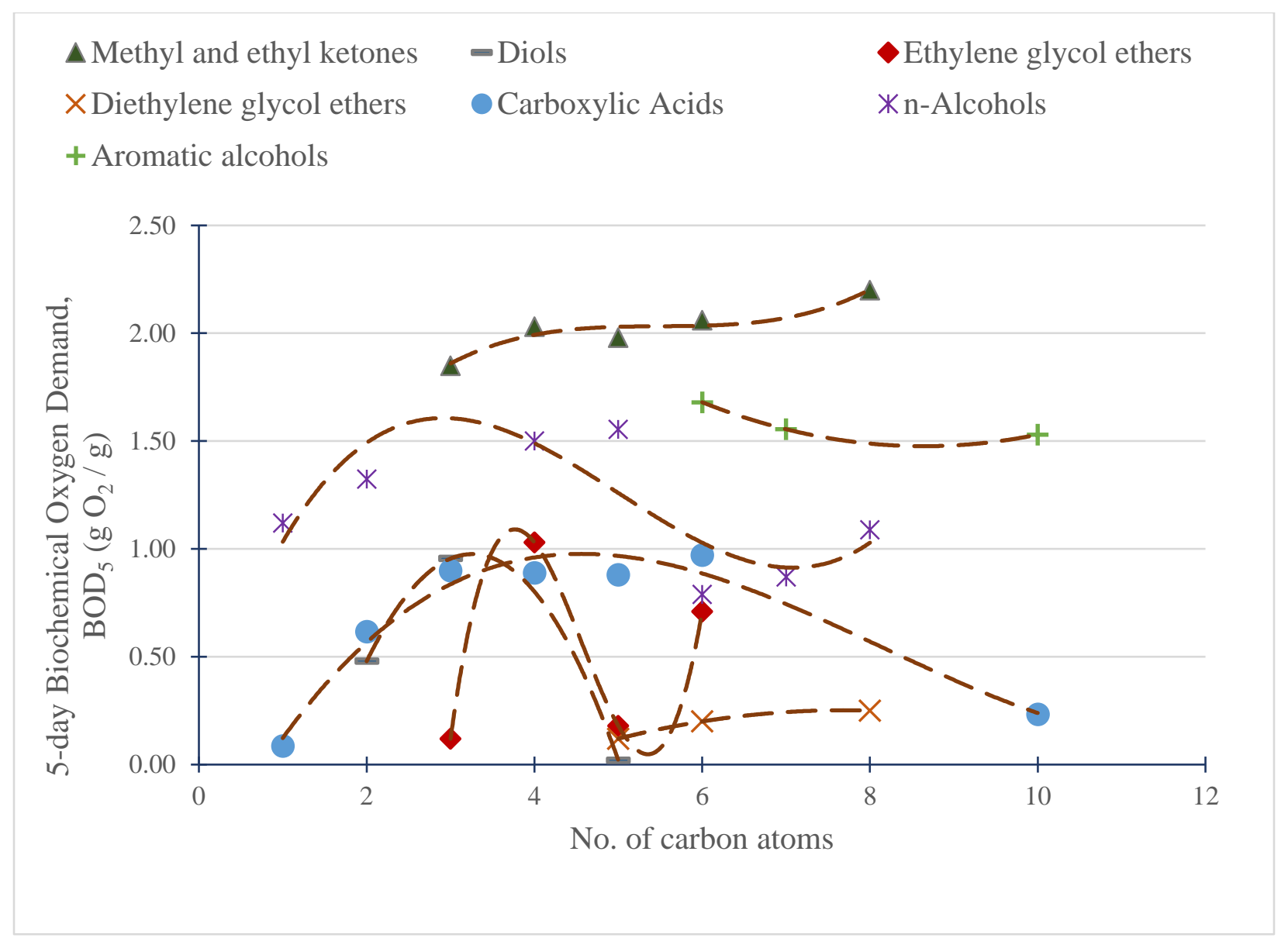

Figure 2. Trend of $\mathrm{BOD}_{5}$ with increasing Number of Carbon Atoms 


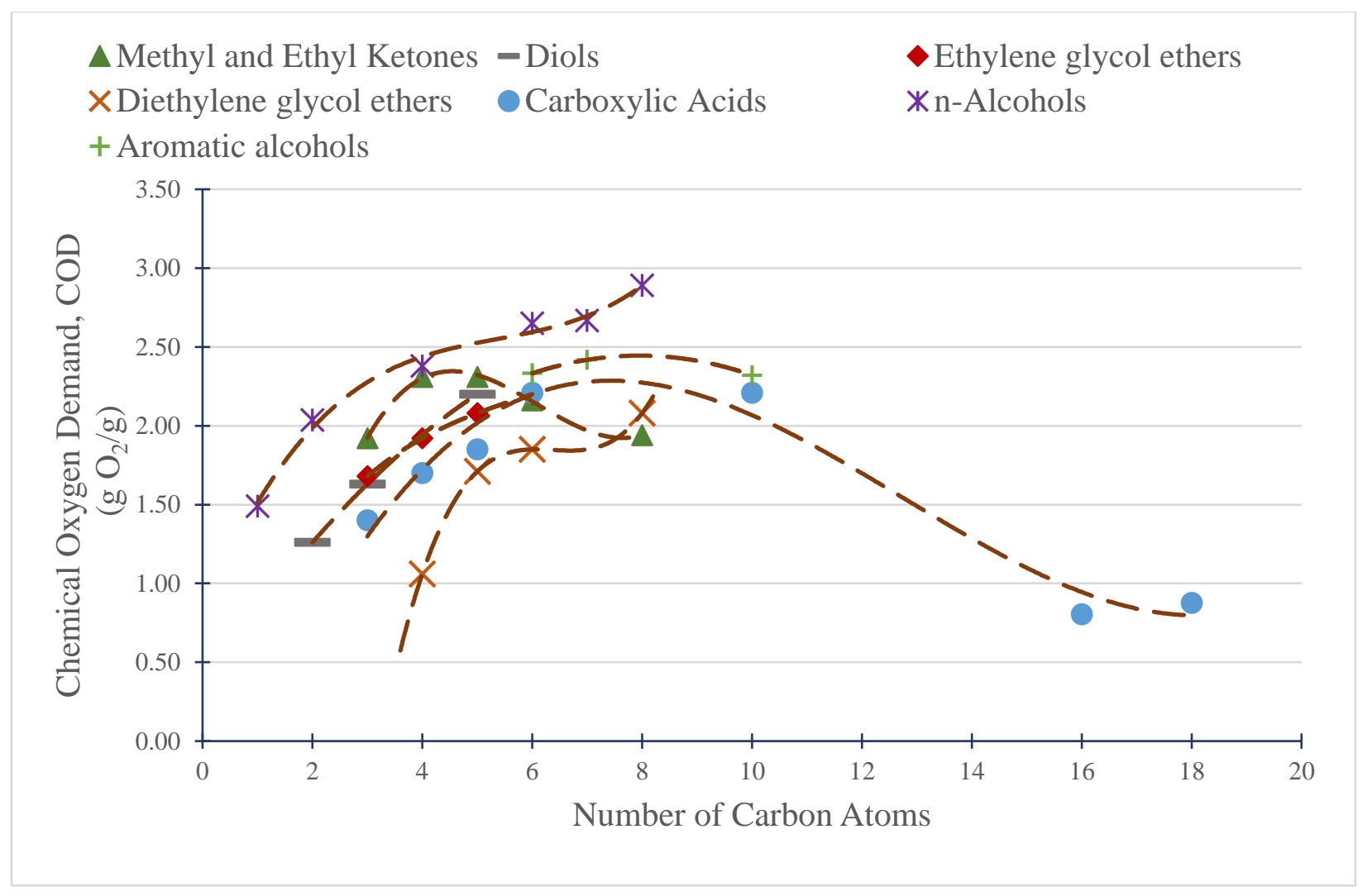

Figure 3. Trend of COD with increasing Number of Carbon Atoms

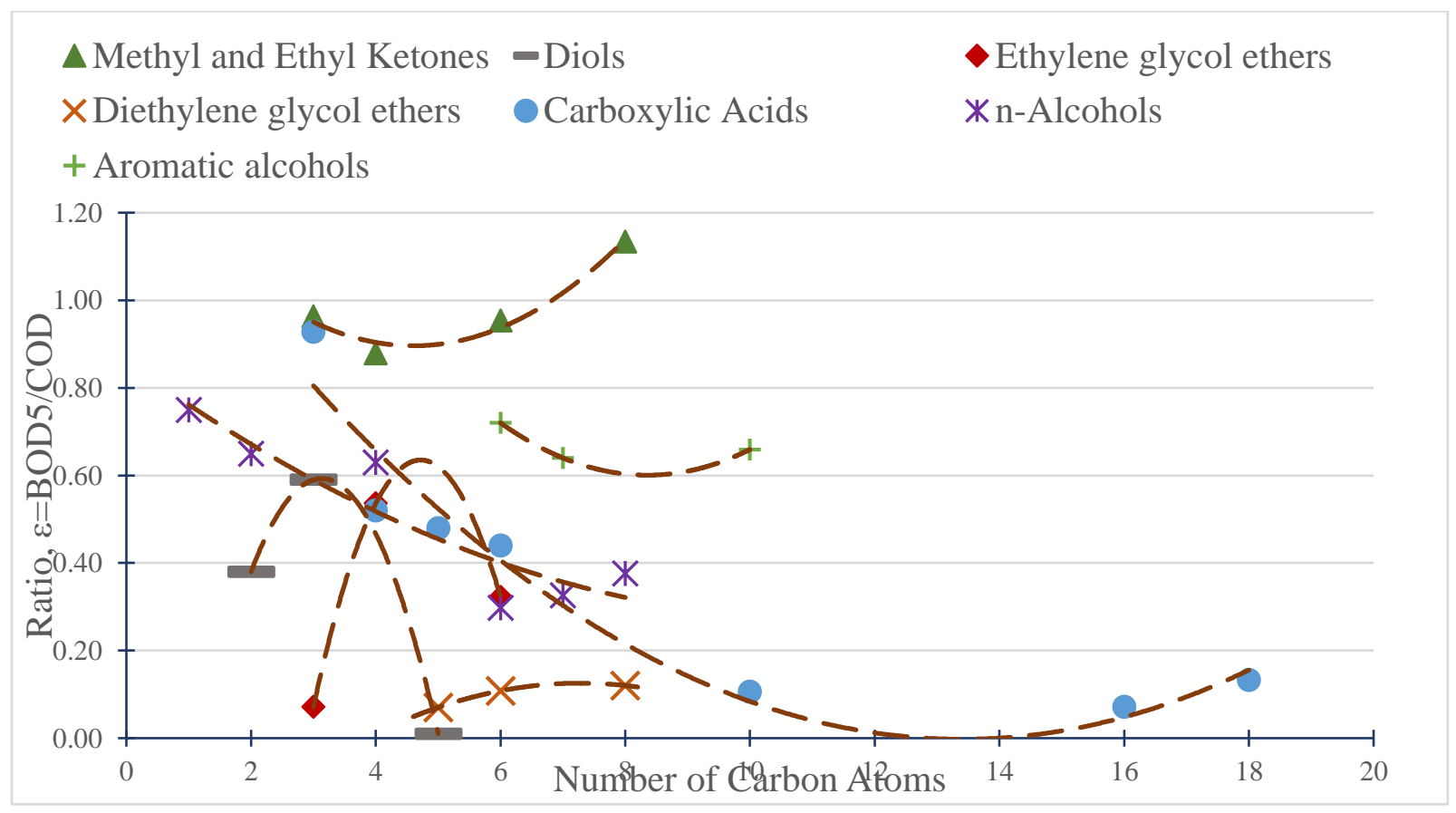

Figure 4. Trend of Ratio of $\mathrm{BOD}_{5}$ to $\mathrm{COD}$ with increasing Number of Carbon Atoms 
Nevertheless, an appropriate function that can model the trend for most organic classes of chemicals was chosen, considering the fact that the ratio of $\mathrm{BOD}_{5}$ to $\mathrm{COD}$, denoted by $\varepsilon$ will always be positive, and could have the form shown below:

$\varepsilon=\left(\sum_{i} N_{i} C_{i}+\sum_{j} M_{j} D_{j}+\sum_{k} O_{k} E_{k}\right)^{2}+\varepsilon_{0}$

$=>\left(\varepsilon-\varepsilon_{0}\right)^{1 / 2}=\sum_{i} N_{i} C_{i}+\sum_{j} M_{j} D_{j}+\sum_{k} O_{k} E_{k}$

In Eq. 8 and Eq.9, $\varepsilon$ is the estimated ratio of the $\mathrm{BOD}_{5}$ to $\mathrm{COD}$ and $\varepsilon_{0}$ is the universal model parameter.

\subsubsection{Parameter Estimation}

All the group contribution parameters $\left(\mathrm{C}_{\mathrm{i}}, \mathrm{D}_{\mathrm{j}}\right.$ and $\left.\mathrm{E}_{\mathrm{k}}\right)$ together with the universal constant $\left(\varepsilon_{0}\right)$ are estimated simultaneously $\left(\mathrm{p} \equiv\left[\mathrm{C}_{\mathrm{i}}, \mathrm{D}_{\mathrm{j}}, \mathrm{E}_{\mathrm{k}}, \varepsilon_{0}\right]\right)$ using a special case of maximum likelihood theory - the least squares method. This is done by minimizing the cost function shown in Eq. 10 wherein $y$ denotes the available experimental data and $\varepsilon(\mathrm{p})$ is the model function shown in Eq. 9. This method assumes that the measurements are independent and identically distributed with white measurement errors having a known standard deviation, $\sigma$ (Gaussian). The objective function, $\mathrm{S}(\mathrm{y}, \mathrm{p})$ to be minimized is, 
$S(y, p)=\frac{(y-\varepsilon(p))^{2}}{\sigma^{2}}$

This minimization is carried out in MATLAB using the fminunc and Isqnonlin functions. The gradient of $\mathrm{S}(\mathrm{y}, \mathrm{p})$ with respect to $\mathrm{p}$ is analytically calculated and supplied in order to define the search direction for parameter estimation using the fminunc function.

\subsection{Model Performance Statistics}

\section{Test of databases one by one}

As a comparison, the first three of the four databases have been tested separately since the measurements are carried out by different research groups / organizations. This check is not performed for Database -4 as the number of groups representing the compounds in the database is more than the number of compounds. Moreover, a combined database comprising of compounds from Databases $1-4$, is also tested. Table 2 presents the different performance statistics for each database.

Table 2 Model Performance Statistics when Parameter Regression is Performed for Each Database Separately

\begin{tabular}{l|cccc}
\hline Database & $\mathbf{R}^{\mathbf{2}}$ & AAD & Number of Compounds & Number of Groups \\
\hline Database - 1 & 0.95 & $55.7 \%$ & 121 & 90 \\
Database - 2 & 0.72 & $33.7 \%$ & 36 & 25 \\
Database - 3 & 0.78 & $324.8 \%$ & 102 & 94 \\
\hline Combination of the & & & 232 & 134 \\
Databases 1 - 4 & 0.69 & $133 \%$ & & \\
(after removing the & & & & \\
common compounds) & & & & \\
\hline
\end{tabular}

The corresponding parity plots are shown in Figure 5 - Figure 8. 


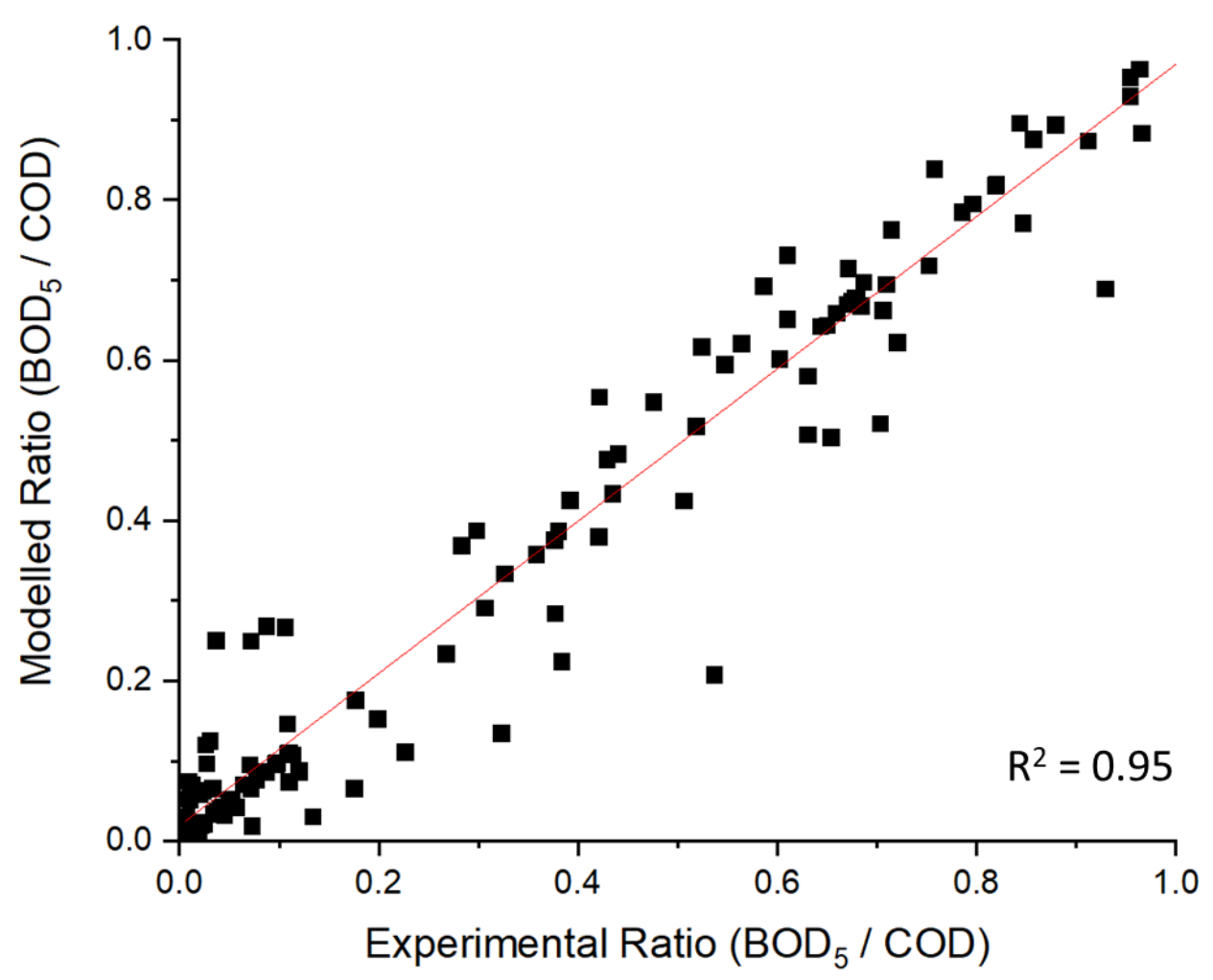

Figure 5. Parity Plot for Database - 1

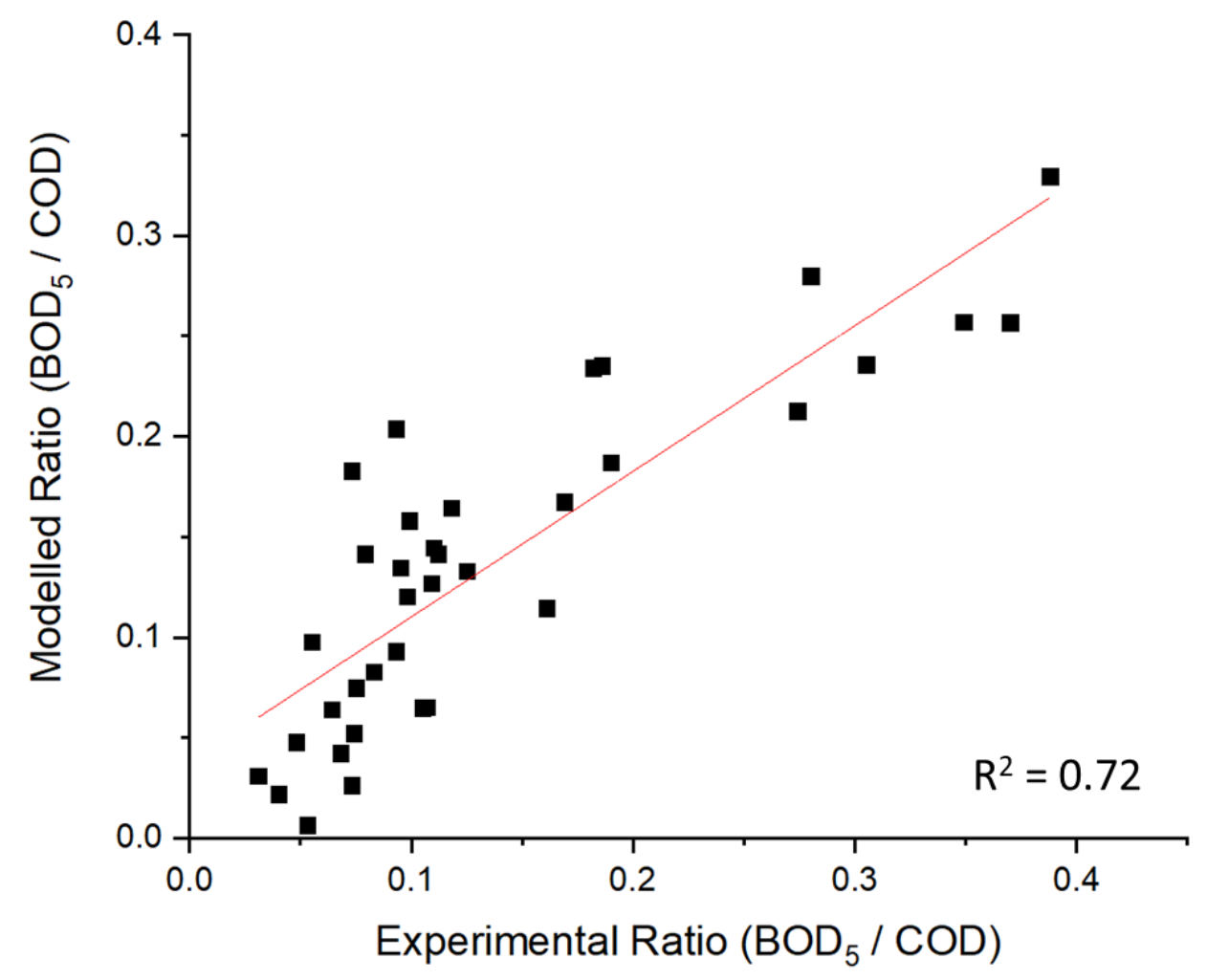

Figure 6. Parity Plot for Database - 2 


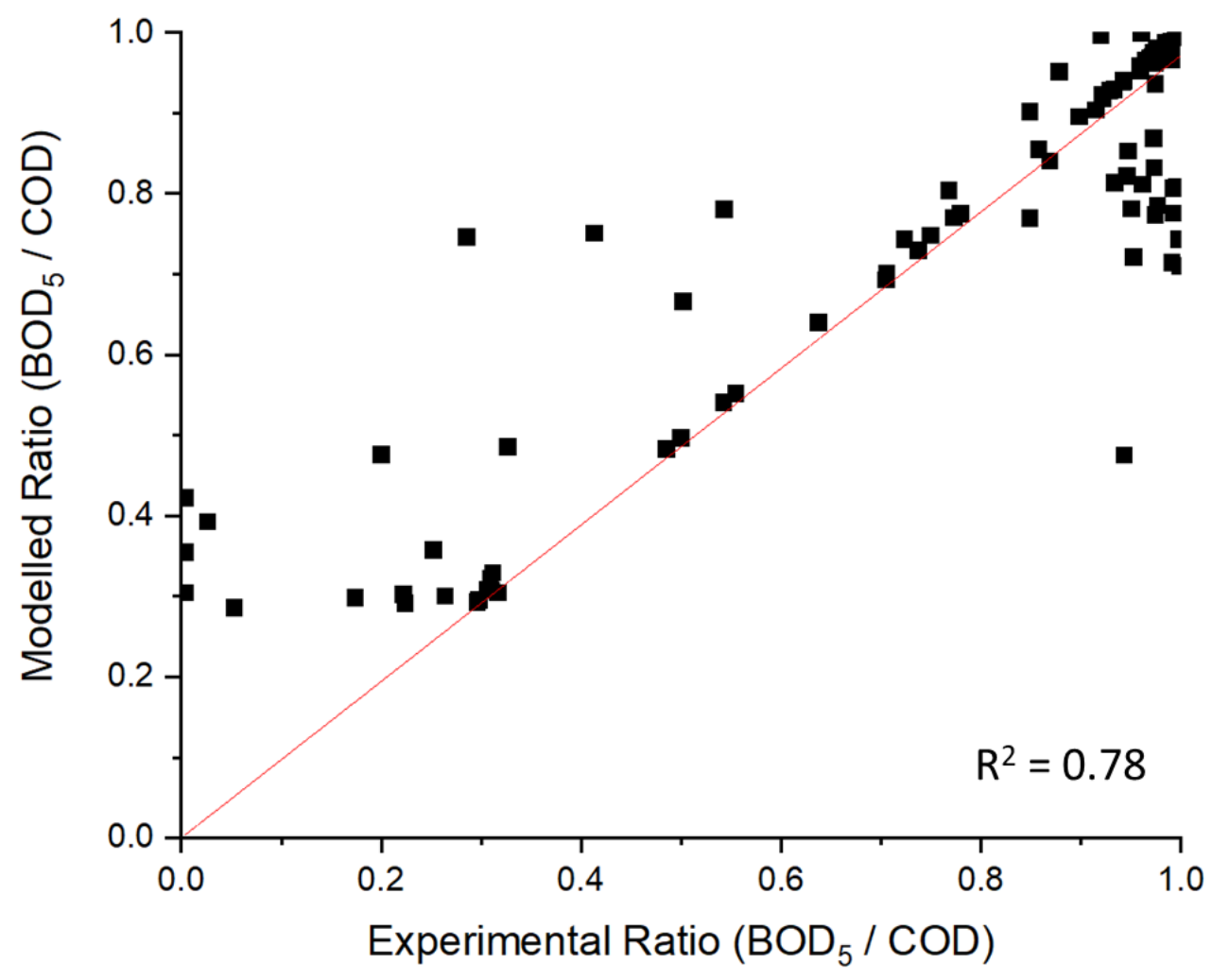

Figure 7. Parity Plot for Database -3

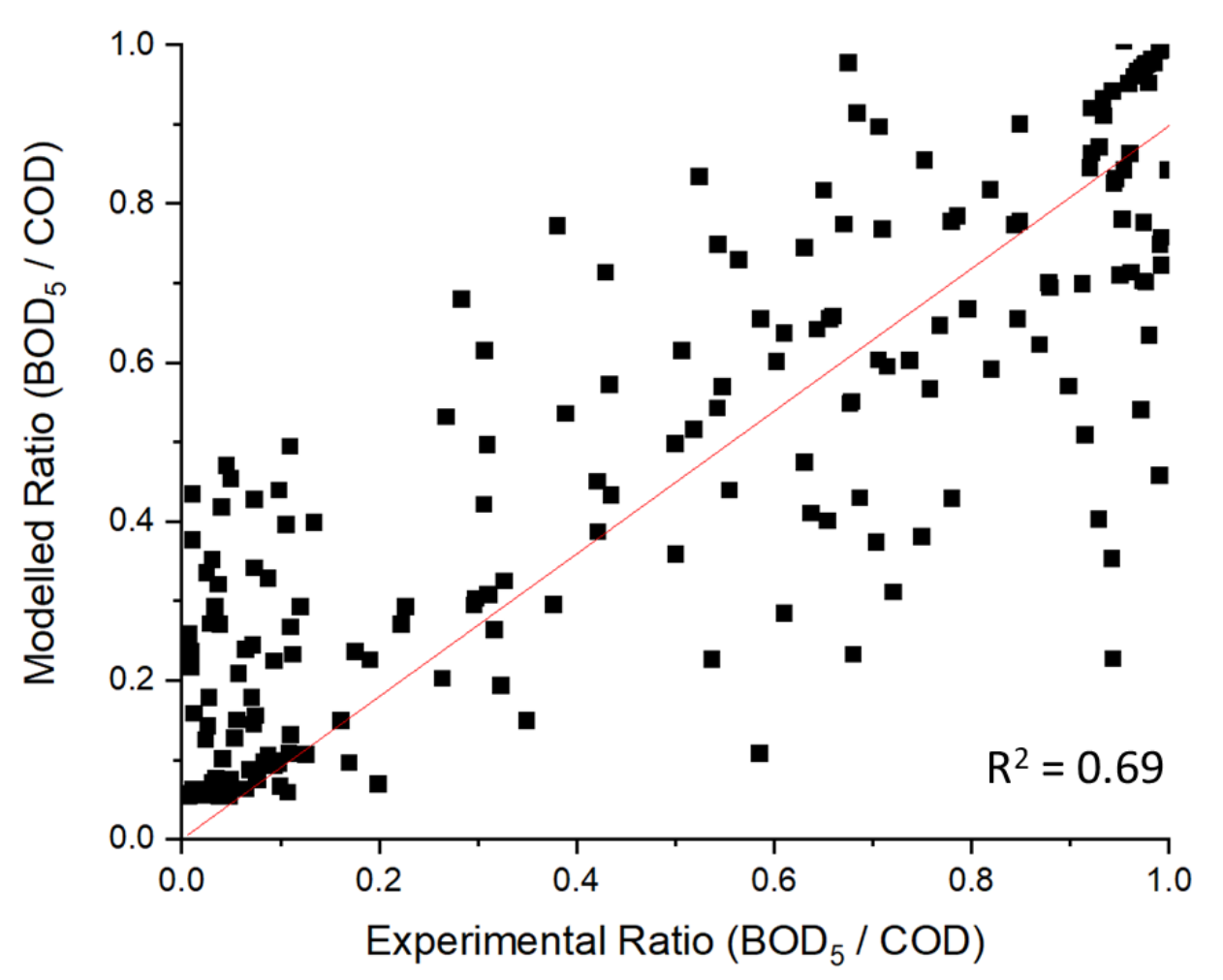

Figure 8. Parity Plot for the Combined Database (1-4) 


\section{Test of pairs of databases}

As the next step, following the results in the previous section, some databases have been mixed in order to further analyze the results and identify the best combinations and the following performances are obtained, as shown in the first four columns of Table 3 . The parity plots for each of the three cases are presented in Figure 9 - Figure 11.

Table 3. Model Performance Statistics when the Parameter Regression is Performed for Different Pairs of Databases

\begin{tabular}{|c|c|c|c|c|c|c|}
\hline Database & $\mathbf{R}^{2}$ & AAD & $\begin{array}{l}\text { Number of } \\
\text { Compounds }\end{array}$ & $\begin{array}{c}\text { Number of } \\
\text { Groups }\end{array}$ & $\begin{array}{c}\text { Number of } \\
\text { Outliers }\end{array}$ & $\begin{array}{c}\mathbf{R}^{2} \text { after } \\
\text { Removing } \\
\text { Outliers }\end{array}$ \\
\hline Database - $1+$ Database -3 & 0.74 & $112 \%$ & 192 & 124 & 17 & 0.85 \\
\hline Database - $2+$ Database -3 & 0.91 & $16 \%$ & 106 & 99 & 9 & -- \\
\hline Database - $1+$ Database - 2 & 0.9 & $30 \%$ & 140 & 99 & 10 & 0.95 \\
\hline
\end{tabular}

Moreover, for each of these combinations shown in Table 3, the number of outliers using the definition of Cook's distance ${ }^{26}$, which shows the influence of each observation on the modelled values, have been determined. According to this definition, an observation is classified as an outlier if it exceeds three times of the mean Cook's distance. The performance of the model has been calculated again with those outliers removed. Sometimes, for small databases after deleting the outliers, the number of groups can become more than the number of compounds. This is the case for the 'Database $-2+$ Database -3 ' combination and hence the parameters cannot be estimated in that case. 


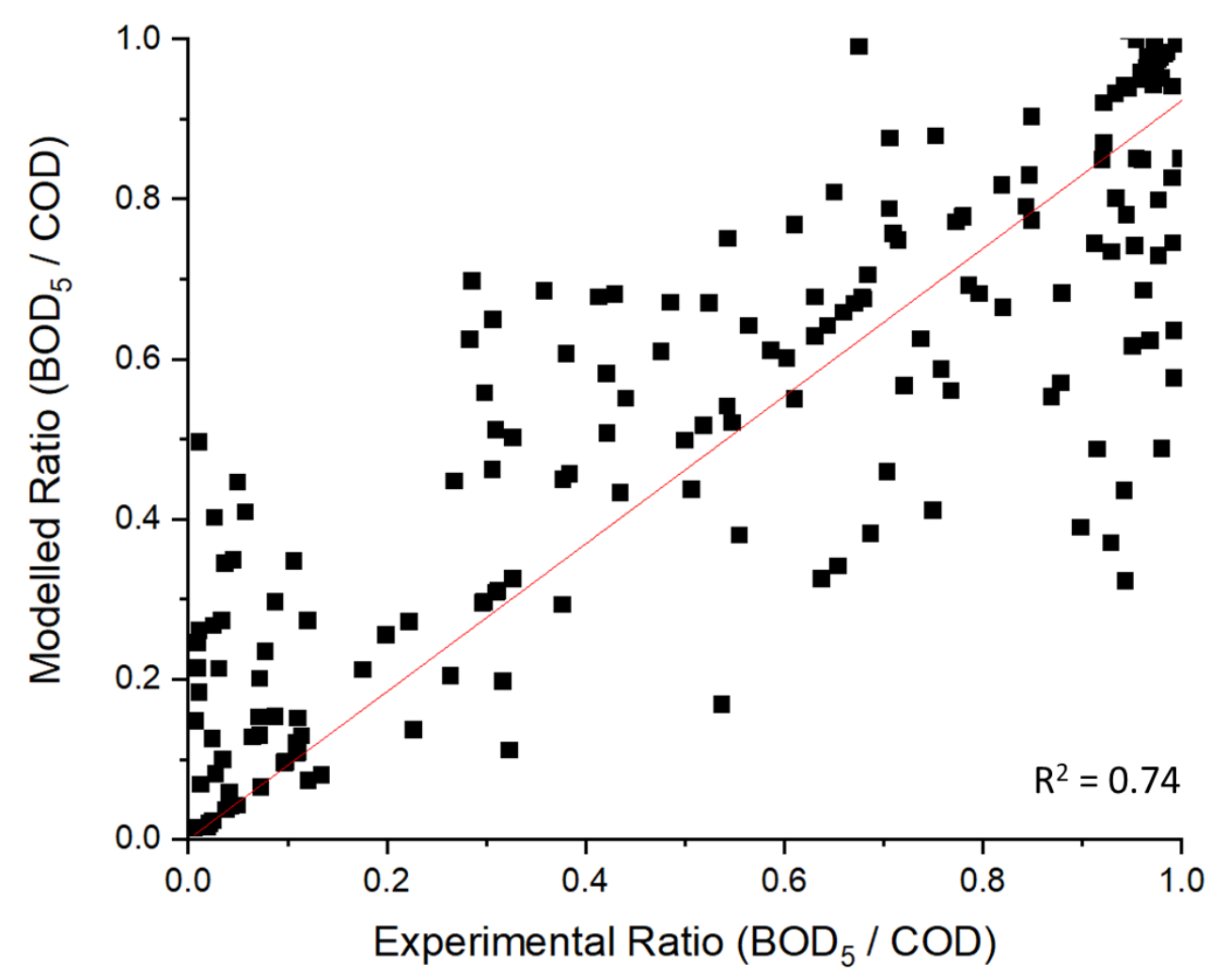

Figure 9. Parity Plot for Database $-1+$ Database -3

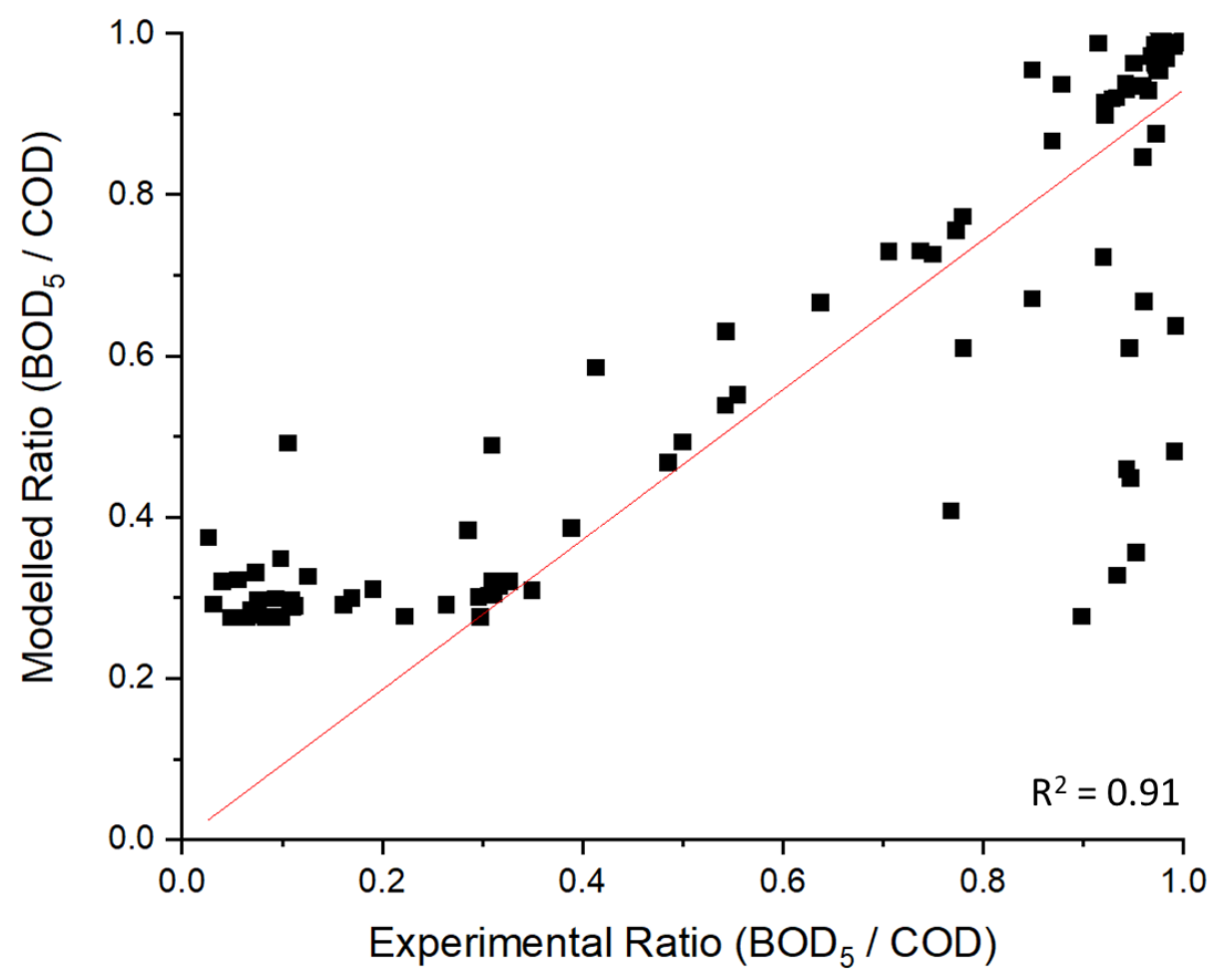

Figure 10. Parity Plot for Database $-2+$ Database -3 


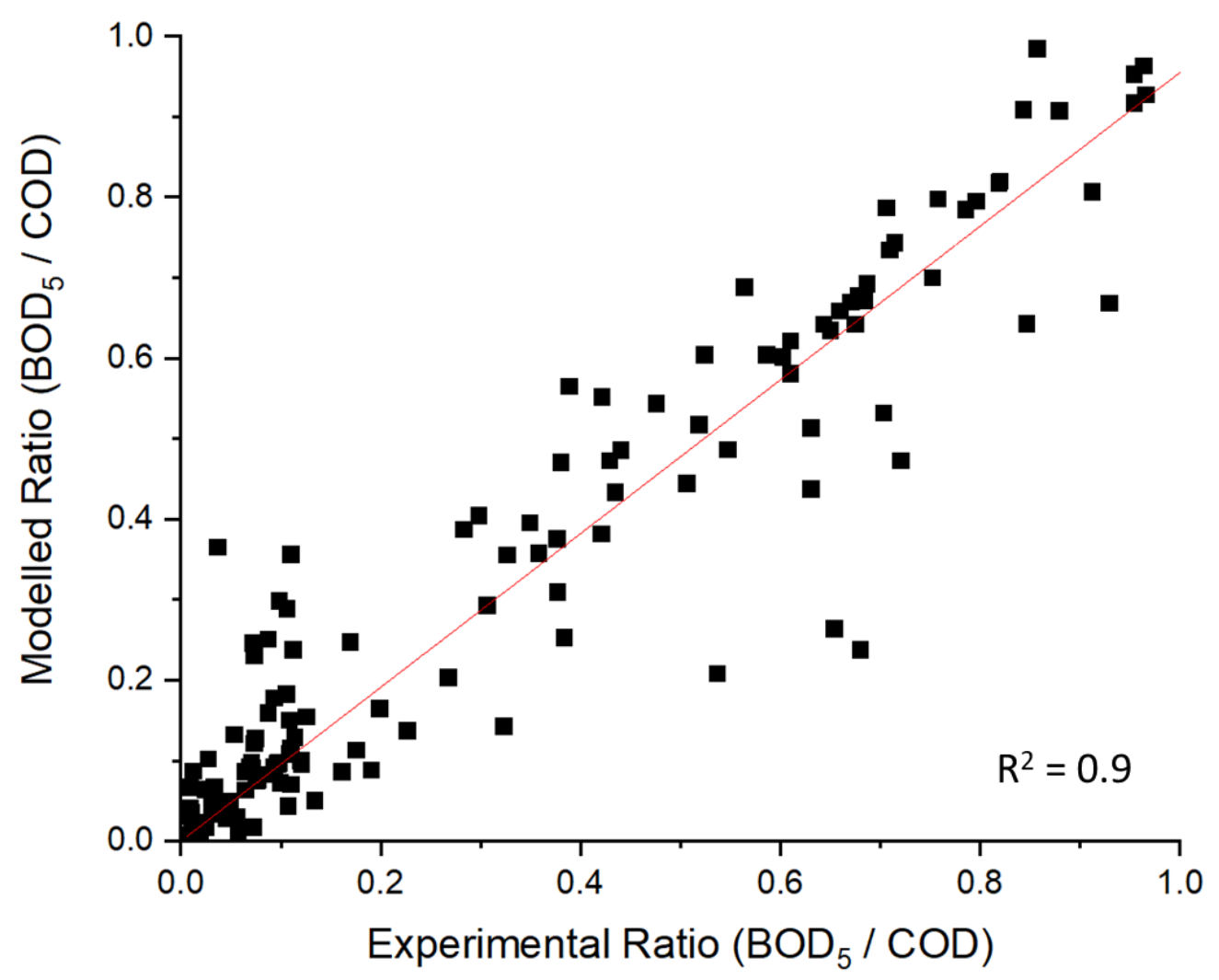

Figure 9. Parity Plot for 'Database $-1+$ Database -2 '

The performance of the mix of two databases looks better compared to the performance of the total database. The combination 'Database $-2+$ Database -3 ' has a good regression coefficient and average absolute deviation but fewer compounds in the region from $0.4-0.6$. Most of the compounds in this combination of datasets are either highly biodegradable, wherein the ratio is greater than 0.8 or highly non-biodegradable, wherein the ratio is less than 0.2 .

However, the combination 'Database $-1+$ Database -2 ', also has a good performance and the compounds in this dataset can be represented with the same number of groups as 'Database $2+$ Database -3 .

Overall, the best performance is obtained with 'Database $-1+$ Database -2 ' after the removal of 12 outliers. The mix 'Database $-1+$ Database -3 ' is less appealing. This could be due to a 
quality issue in the Database 3. Some of the compounds from Database 3 have high ratios for $\mathrm{BOD}_{5}$ to COD. For instance, monocholorbenzene, tetrahydrofuran, diuron, metolachlor and propachlor have a ratio of greater than 0.9 suggesting that they are readily biodegradable. This is not expected given that these are aromatic and halogenated compounds. Therefore, the parameter regression performed using 'Database $-1+$ Database -2 ' is considered as the final recommended one and it is used further to predict the biodegradability of other organic compounds.

\subsection{Model Validation}

The developed model is then further validated. For this, a database containing 45 compounds provided by Syngenta AG was used. However, only 10 out of these 45 compounds could be represented by the groups used to develop the model. For 7 out of these 10 compounds the predictions were quite good ( $\mathrm{AAE}<=0.1$ ). While, for the remaining three compounds the $\mathrm{AE}$ was $0.38,0.46$ and 1.38 .

Furthermore, the model is redeveloped by including the compounds from the Syngenta AG database in the parameter estimation step. The parameters for this model are available in Table 4.

Table 4. Group Contribution Model Parameters

\begin{tabular}{lc}
\hline Groups & Parameters \\
\hline Universal Constant & $-0,0023$ \\
\hline $\mathbf{\varepsilon 0}$ & \\
1st Order Groups & 0,4687 \\
\hline $\mathbf{C H 3}$ & $-0,0261$ \\
$\mathbf{C H} 2$ & $-0,4215$ \\
$\mathbf{C H}$ & $-1,4598$ \\
$\mathbf{C}$ & $-0,2305$ \\
$\mathbf{C H} 2=\mathbf{C H}$ & $-1,9589$ \\
$\mathbf{C H}=\mathbf{C H}$ & $-0,7647$ \\
$\mathbf{C H} 2=\mathbf{C}$ & $-1,4002$ \\
$\mathbf{C H}=\mathbf{C}$ & $-0,1847$ \\
$\mathbf{C H} \# \mathbf{C}$ &
\end{tabular}




\begin{tabular}{|c|c|}
\hline $\mathbf{a C H}$ & 0,1025 \\
\hline $\mathbf{a C}$ & 0,0893 \\
\hline $\mathbf{a C}$ & 0,0219 \\
\hline $\mathbf{a C}$ & 0,2528 \\
\hline aN & $-0,1759$ \\
\hline aC-CH3 & 0,3047 \\
\hline $\mathrm{aC}-\mathrm{CH} 2$ & $-0,1398$ \\
\hline aC-C & $-0,7655$ \\
\hline $\mathrm{aC}-\mathrm{CH}=\mathrm{CH} 2$ & 0,1482 \\
\hline OH & 0,3620 \\
\hline aC-OH & 0,2026 \\
\hline $\mathrm{COOH}$ & 0,4134 \\
\hline aC-COOH & 0,3057 \\
\hline СН3CO & 0,5140 \\
\hline СH2CO & 0,0696 \\
\hline $\mathrm{CCO}$ & 0,8638 \\
\hline aC-CO & $-0,7032$ \\
\hline CHO & 0,1174 \\
\hline aC-CHO & 0,3934 \\
\hline СH3COO & 0,2852 \\
\hline CH2COO & 0,0126 \\
\hline aC-COO & $-0,0178$ \\
\hline $\mathrm{COO}$ & $-0,1714$ \\
\hline CH3O & 0,2643 \\
\hline CH2O & $-0,1078$ \\
\hline CH-O & $-1,0281$ \\
\hline aC-O & $-0,4774$ \\
\hline $\mathrm{CH} 2 \mathrm{NH} 2$ & $-0,0017$ \\
\hline CHNH2 & 0,0916 \\
\hline CH2NH & $-1,0746$ \\
\hline CHNH & 0,1231 \\
\hline CH2N & $-1,3474$ \\
\hline aC-NH2 & 0,1886 \\
\hline aC-NH & 0,1770 \\
\hline NH2 & $-0,3386$ \\
\hline $\mathrm{CH}=\mathrm{N}$ & $-0,4524$ \\
\hline $\mathbf{C}=\mathbf{N}$ & 0,4633 \\
\hline $\mathbf{C N}$ & 0,4759 \\
\hline aC-NO2 & $-0,1081$ \\
\hline CONH2 & 0,4301 \\
\hline aC-CONH2 & $-0,2204$ \\
\hline $\mathrm{aC}-\mathrm{NH}(\mathrm{CO}) \mathrm{H}$ & 0,5000 \\
\hline aC-CONH & 0,0066 \\
\hline aC-NHCONH & $-0,2238$ \\
\hline NHCO & $-0,5998$ \\
\hline $\mathrm{CH} 2 \mathrm{Cl}$ & $-0,1549$ \\
\hline
\end{tabular}




\begin{tabular}{|c|c|}
\hline CHF2 & $-0,0989$ \\
\hline CF3 & 1,4849 \\
\hline aC-Cl & $-0,0082$ \\
\hline aC-F & $-0,1338$ \\
\hline aC-Br & $-0,2183$ \\
\hline $\mathrm{Br}$ & 0,3023 \\
\hline $\mathbf{F}$ & 0,1669 \\
\hline Cl & $-0,3243$ \\
\hline ОСН2СН2ОН & 0,0497 \\
\hline ОСН2СНОН & $-0,7216$ \\
\hline aC-SO2 & $-0,1467$ \\
\hline С2H3O & $-0,3403$ \\
\hline СH2(cyc) & $-0,0039$ \\
\hline CH(cyc) & 0,0198 \\
\hline C(cyc) & $-0,2749$ \\
\hline $\mathrm{CH}=\mathrm{CH}(\mathrm{cyc})$ & 0,0703 \\
\hline $\mathrm{CH}=\mathrm{C}(\mathrm{cyc})$ & $-0,4184$ \\
\hline $\mathrm{C}=\mathrm{C}(\mathrm{cyc})$ & $-0,0560$ \\
\hline NH(cyc) & 0,1912 \\
\hline $\mathbf{N}(\mathbf{c y c})$ & $-0,1442$ \\
\hline $\mathrm{CH}=\mathrm{N}(\mathrm{cyc})$ & 0,2453 \\
\hline $\mathrm{C}=\mathrm{N}(\mathbf{c y c})$ & 0,5724 \\
\hline$O($ cyc) & 0,1994 \\
\hline $\mathrm{CO}(\mathrm{cyc})$ & $-0,0062$ \\
\hline$>\mathbf{N H}$ & 0,0417 \\
\hline$-0-$ & 0,0126 \\
\hline$>\mathrm{CO}$ & 0,2190 \\
\hline CH-N & $-0,0989$ \\
\hline $\mathbf{a C}=\mathbf{O}$ & 0,5174 \\
\hline aN- & 0,5174 \\
\hline $\mathbf{N a}$ & $-0,0095$ \\
\hline \multicolumn{2}{|l|}{ 2nd Order Groups } \\
\hline (CH3)2CH & $-0,0462$ \\
\hline (CH3)3C & $-0,5713$ \\
\hline $\mathrm{CH3}-\mathrm{CHm}=\mathrm{CHn}(\mathrm{m} . \mathrm{n}$ in $0 . .2)$ & 0,4210 \\
\hline $\mathrm{CH} 2-\mathrm{CHm}=\mathrm{CHn}(\mathrm{m} . \mathrm{n}$ in $0 . .2)$ & 0,8618 \\
\hline СН3СОСН2 & $-0,0025$ \\
\hline СНСООН & 0,5439 \\
\hline СНОН & 0,0492 \\
\hline $\mathrm{COH}$ & $-0,0379$ \\
\hline $\mathrm{CHm}(\mathrm{OH}) \mathrm{CHn}(\mathrm{OH})(\mathrm{m} . \mathrm{n}$ in $0 . .2)$ & 0,0277 \\
\hline $\mathrm{CHm}(\mathrm{OH}) \mathrm{CHn}(\mathrm{NHp})(\mathrm{m} . n . p$ in $0 . .2)$ & 0,1976 \\
\hline $\mathrm{CHm}(\mathrm{NHn})-\mathrm{COOH}(\mathrm{m} . \mathrm{n}$ in $0 . .2)$ & 0,0916 \\
\hline HOOC-CHn-CHm-COOH (n. $m$ in 1..2) & 0,0830 \\
\hline HO-CHn-COOH ( $n$ in 1..2) & 0,0007 \\
\hline CHm-O-CHn=CHp (m.n.p in 0..3) & 0,8638 \\
\hline
\end{tabular}




\begin{tabular}{|c|c|}
\hline $\mathrm{CHm}=\mathrm{CHn}-\mathrm{CN}(\mathrm{m} . \mathrm{n}$ in $0 . .2)$ & 0,4759 \\
\hline $\mathrm{CHm}=\mathrm{CHn}-\mathrm{COOH}(\mathrm{m} . \mathrm{n}$ in 0.2$)$ & 1,0097 \\
\hline $\mathrm{aC}-\mathrm{CHn}-\mathrm{O}-(\mathrm{n}$ in $1 . .2)$ & 0,0155 \\
\hline aC-CHn-OH ( $n$ in 1..2) & 0,0687 \\
\hline aC-SO2-OH & $-0,3174$ \\
\hline aC-C(CH3)3 & $-0,7954$ \\
\hline aC-CF3 & $-0,0644$ \\
\hline$(\mathrm{CHn}=\mathrm{C})$ cyc-CO- $(\mathrm{n}$ in $0 . .2)$ & 0,2086 \\
\hline$(\mathrm{CHn}=\mathrm{C})$ cyc-CH3 (n in $0 . .2)$ & 0,0305 \\
\hline СНсус-СН3 & 0,1851 \\
\hline СНcyc-СH2 & 0,0532 \\
\hline CHcyc-OH & $-0,2409$ \\
\hline CHcyc-NH2 & 0,3030 \\
\hline CHcyc-NH-CHn (n in 0..3) & 0,2077 \\
\hline CHcyc-CO & $-0,0383$ \\
\hline CHсус-COO & $-0,0095$ \\
\hline >Ncyc-CH3 & $-0,4166$ \\
\hline$>$ Ncyc-CH2 & $-0,3503$ \\
\hline AROMRINGs1s2 & $-0,1700$ \\
\hline AROMRINGs1s3 & $-0,0823$ \\
\hline AROMRINGs1s4 & $-0,2978$ \\
\hline AROMRINGs1s2s3 & $-0,7233$ \\
\hline AROMRINGs1s2s4 & $-0,6885$ \\
\hline AROMRINGs1s3s5 & $-0,9197$ \\
\hline AROMRINGs1s2s3s5 & $-0,6973$ \\
\hline PYRIDINEs2s3 & $-0,0057$ \\
\hline PYRIDINEs2s4 & 0,1333 \\
\hline PYRIDINEs3s5 & $-0,1831$ \\
\hline PYRIDINEs2s3s6 & 0,0987 \\
\hline aC-SO2NHn $(n>=0 ; n<3)$ & $-0,0191$ \\
\hline aC-SO2NHn $(n>=0 ; n<3)$ & 0,2333 \\
\hline \multicolumn{2}{|l|}{ 3rd Order Groups } \\
\hline $\mathrm{aC}-(\mathrm{CHn}=\mathrm{CHm}) \mathrm{cyc}$ (fused rings) (n.m in 0..1) & 0,0305 \\
\hline aC-CHncyc (different rings) (n in $0 . .1$ ) & 0,3030 \\
\hline CH multiring & 0,0698 \\
\hline C multiring & $-0,2749$ \\
\hline $\mathrm{aC}-\mathrm{CHm}-\mathrm{aC}$ (different rings) ( $\mathrm{m}$ in $0 . .2$ ) & 0,5350 \\
\hline aC-CO- $(\mathrm{C}=\mathrm{CHn}) \mathrm{cyc}($ different rings) $(\mathrm{n}$ in $\mathbf{0 . . 1})$ & 0,3430 \\
\hline aC-CO-CHncyc (different rings) ( $\mathrm{n}$ in $0 . .1$ ) & $-0,0689$ \\
\hline aC-NHncyc (fused rings) ( $\mathrm{n}$ in $0 . .1$ ) & 0,0213 \\
\hline aC-NH-aC (different rings) & 0,1770 \\
\hline aC-(N=CHn)cyc (fused rings) ( $n$ in $0 . .1)$ & 0,1110 \\
\hline AROM.FUSED[2] & $-0,0001$ \\
\hline AROM.FUSED[2]s1 & $-0,2849$ \\
\hline PYRIDINE.FUSED[2] & 0,3116 \\
\hline
\end{tabular}


A comparison of the group representation in the model based on 'Database $-1+$ Database 2 ' and the new model based on 'Database $-1+$ Database $-2+$ Syngenta AG compounds' is shown in Table 5.

Table 5. Comparison of Group Representation and Performance Statistics between Model based on 'Database - $1+$ Database -2 ' and Model based on 'Database $-1+$ Database $-2+$ Syngenta AG compounds'

\begin{tabular}{|c|c|c|c|}
\hline Parameters & Representation & $\begin{array}{l}\text { Model based on Database }-1+ \\
\text { Database }-2+\text { Syngenta AG } \\
\text { Database }\end{array}$ & $\begin{array}{l}\text { Model } \quad \text { based } \\
\text { Database }-1 \text { + Database }-2\end{array}$ \\
\hline & & Number & Number \\
\hline $\begin{array}{l}1^{\text {st }} \text { Order Group } \\
\text { Contribution }\end{array}$ & $C_{i}$ & 86 & 58 \\
\hline $\begin{array}{l}2^{\text {nd }} \text { Order Group } \\
\text { Contribution }\end{array}$ & $D_{j}$ & 45 & 28 \\
\hline $\begin{array}{l}3^{\text {rd }} \text { Order Group } \\
\text { Contribution }\end{array}$ & $E_{k}$ & 13 & 5 \\
\hline Universal Constant & $\varepsilon_{0}$ & 1 & 1 \\
\hline Model & $A A E$ & 0.04 & 0.05 \\
\hline $\begin{array}{l}\text { Performance } \\
\text { Statistics }\end{array}$ & $R^{2}$ & 0.90 & 0.92 \\
\hline
\end{tabular}

\section{Application Examples}

In this section, two examples are provided where the developed GC model based on parameters regressed using the combined dataset comprising of 'Database $-1+$ Database $-2+$ Syngenta AG compounds' is employed. The performance of the model for determining the ratio of $\mathrm{BOD}_{5}$ to COD for these two compounds and the pertinent calculations are presented in Table 6 . 
Table 6. Biodegradability Calculation for Two Compounds Using the Developed Model

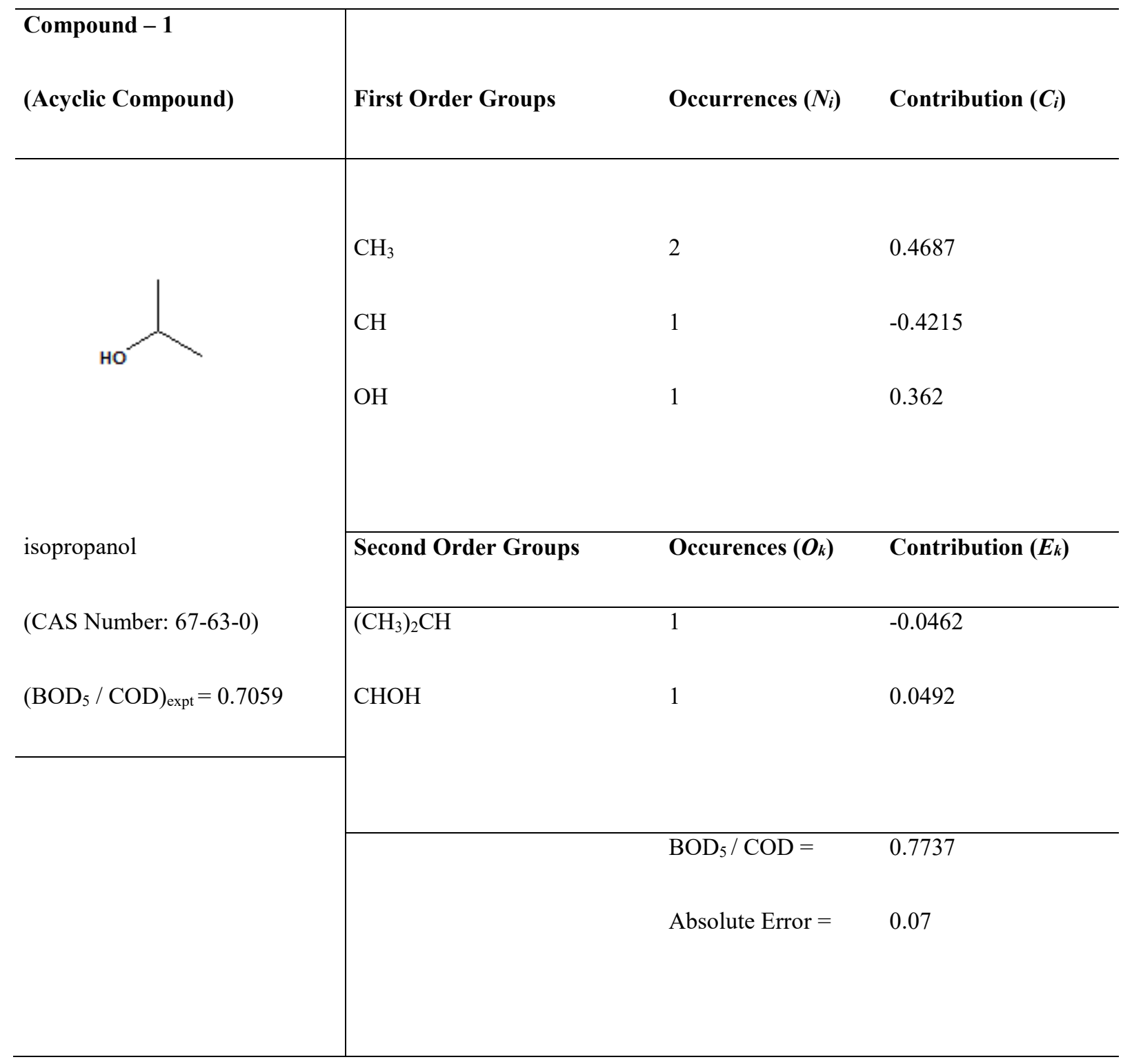

\begin{tabular}{l|lll}
\hline Compound - 2 & First Order Groups & Occurences $\left(N_{i}\right)$ & Contribution $\left(\boldsymbol{C}_{\boldsymbol{i}}\right)$ \\
\hline (Aromatic Compound) & & 3 & \\
\hline $\mathrm{aCH}$ & 1 & 0.1025 \\
& & 2 & -0.0082
\end{tabular}




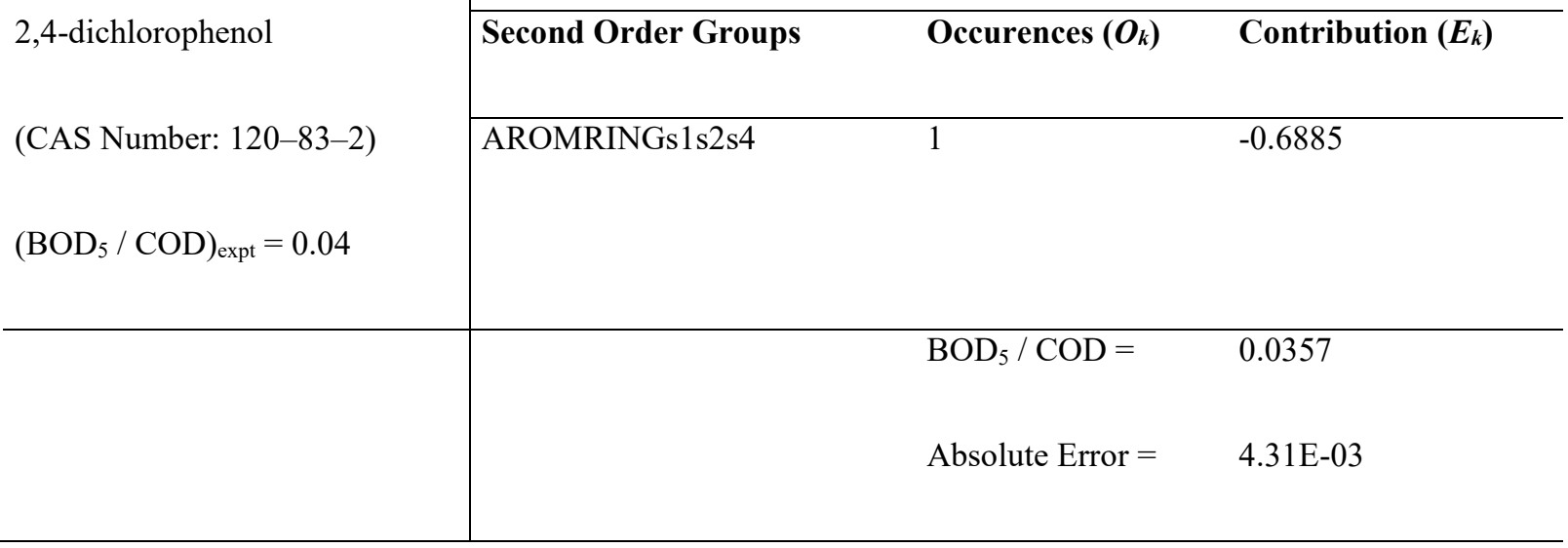

Besides predicting the value of this ratio, the model is also able to correctly classify $96 \%$ of the compounds in the database 'Database $-1+$ Database $-2+$ Syngenta AG compounds' as 'readily biodegradable' or 'not readily biodegradable'. A ratio of greater than 0.5 suggests biodegradability of the compound and can serve as a first screening test for the biodegradability of a specific chemical.

\section{Conclusion}

A group-contribution (GC) based property model has been developed with the objective of providing reliable and quick estimation of the biodegradability for a wide range of organic compounds. The model can be used for applications in sustainable chemical product design and for substituting hazardous chemicals with their greener counterparts. The prediction of the ratio of $\mathrm{BOD}_{5}$ to $\mathrm{COD}$ using the developed $\mathrm{GC}$ model is satisfactory $\left(\mathrm{R}^{2}=0.92, \mathrm{AAE}=0.05\right)$. However, the quality of the data compiled in the form of the four databases from various sources in the literature, which has been used to develop the model, is unknown. This poses a limitation on developing such models that are highly dependent on the data.

Motivated by the results obtained in this work, future work could focus on the property modelling combining machine learning algorithms with GC towards further improving the 
prediction accuracy of the model. Machine learning algorithms could help in handling the exceptional cases wherein the modelled value of the property deviates significantly from the observed (or experimental) values. Herein, the structural group information could be provided for training the machine learning-based model, thus giving rise to hybrid models that could have an enhanced performance.

\section{SUPPORTING INFORMATION}

I.

Databases to Develop the Model for Biodegradation

- $\quad$ Table S1. Database - 1: Simple Acyclic Compounds and Aromatics

- $\quad$ Table S2. Database - 2: Benzene Ring - Containing Aromatics

- Table S3. Database - 3: Acyclic Compounds, Aromatics and Complex Pesticides

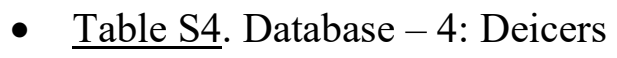

II. List of Abbreviations

\section{AUTHOR INFORMATION}

\section{Corresponding Author}

Georgios M. Kontogeorgis. Phone: +45 452528 59, e-mail: gk@kt.dtu.dk.

\section{Notes}

The authors declare no competing financial interest.

\section{ABBREVIATIONS}

The list of abbreviations are available in Section B of the Supporting Information.

\section{ACKNOWLEDGEMENT}

The authors are grateful to Syngenta AG for providing useful data which were considered in the models' development and validation. 


\section{REFERENCES}

(1) Speight, J. G. Environmental Organic Chemistry for Engineers; 2017.

(2) Organization for Economic Cooperation and Development (OECD). Test No. 301: Ready Biodegradability. In OECD Guidelines for Testing of Chemicals, Section 3; 2018, DOI 10.1787/9789264070349-en.

(3) Wik, A.; Montero, R. M.; Dilhac, B. How to bring your registration dossier in compliance with REACH - ECHA (accessed Sep 8, 2019).

(4) Jördening, H. J.; Winter, J. Environmental Biotechnology: Concepts and Applications; 2005, DOI 10.1002/3527604286.

(5) Quayle, W. C.; Fattore, A.; Zandona, R.; Christen, E. W.; Arienzo, M. Evaluation of Organic Matter Concentration in Winery Wastewater: A Case Study from Australia. Water Sci. Technol. 2009, 60 (10), 2521-2528, DOI 10.2166/wst.2009.688.

(6) General Electric Power and Water. Correlating Total Organic Carbon (TOC) to Biochemical (BOD5) and Chemical Oxygen Demand (COD); 2015.

(7) Grammatica P, Pavan M, Consolaro F, Connsonni V, T. R. QSAR Modeling of the Biodegradation by Holistic Molecular Descriptors. In 9th International Workshop on QSARs, Bourgas, Bulgaria; 2000; p 36.

(8) Pavan, M.; Worth, A.; Netzeva, T. I. Review of QSAR Models for Bioconcentration; 2006.

(9) Boethling, R. S.; Howard, P. H.; Meylan, W.; Stiteler, W.; Beauman, J.; Tirado, N. Group Contribution Method for Predicting Probability and Rate of Aerobic Biodegradation. Environ. Sci. Technol. 1994, 28 (3), 459-465, DOI $10.1021 / \mathrm{es} 00052 \mathrm{a} 018$ 
(10) U.S. Environmental Protection Agency. EPI Suite ${ }^{\mathrm{TM}}$-Estimation Program Interface (accessed Sep 3, 2019).

(11) C.J. van Leeuwen, T. G. V. Risk Assessment of Chemicals: An Introduction, Second Edi.; Springer, 2009; Vol. 15, DOI 10.1080/10807030802616012.

(12) Gani, R.; Hytoft, G.; Jaksland, C.; Jensen, A. K. An Integrated Computer Aided System for Integrated Design of Chemical Processes. Comput. Chem. Eng. 1997, 21 (10), 11351146, DOI 10.1016/S0098-1354(96)00324-9.

(13) Gamberger, D.; Sekuak, S.; Sabljič, A. Modelling Biodegradation by an Example-Based Learning System. Informatica 1987, 17, 157-166.

(14) Gamberger, D.; Horvatić, D.; Sekušak, S.; Sabljić, A. Applications of Experts' Judgement to Derive Structure-Biodegradation Relationships. Environmental Science and Pollution Research. 1996, pp 224-228, DOI 10.1007/BF02986965.

(15) Hukkerikar, A. S.; Sarup, B.; Ten Kate, A.; Abildskov, J.; Sin, G.; Gani, R. GroupContribution $+(\mathrm{GC}+)$ Based Estimation of Properties of Pure Components: Improved Property Estimation and Uncertainty Analysis. Fluid Phase Equilib. 2012, 321, 25-43, DOI 10.1016/j.fluid.2012.02.010.

(16) Marrero, J.; Gani, R. Group-Contribution Based Estimation of Pure Component Properties. Fluid Phase Equilib. 2001, 183-184, 183-208, DOI 10.1016/S03783812(01)00431-9.

(17) Bridié, A. L.; Wolff, C. J. M.; Winter, M. BOD and COD of Some Petrochemicals. Water Res. 1979, 13 (7), 627-630, DOI 10.1016/0043-1354(79)90011-3.

(18) Haandel, A; Lubbe, J. Handbook of Biological Wastewater Treatment; IWA Publishing, 2012. 
(19) Pitter, P., Chudoba, J. Biodegradability of Organic Substances in the Aquatic Environment; CRC Press: Boca Raton, Florida, 1990.

(20) Verschueren, K. Handbook of Environmental Data on Organic Chemicals. Soil Sci. 1985, 139 (4), 376, DOI 10.1097/00010694-198504000-00014.

(21) Cvetnic, M.; Juretic Perisic, D.; Kovacic, M.; Kusic, H.; Dermadi, J.; Horvat, S.; Bolanca, T.; Marin, V.; Karamanis, P.; Loncaric Bozic, A. Prediction of Biodegradability of Aromatics in Water Using QSAR Modeling. Ecotoxicol. Environ. Saf. 2017, 139, 139-149, DOI 10.1016/j.ecoenv.2017.01.031.

(22) Wernet, G.; Hellweg, S.; Fischer, U.; Papadokonstantakis, S.; Hungerbühler, K. Molecular-Structure-Based Models of Chemical Inventories Using Neural Networks. Environ. Sci. Technol. 2008, 42 (17), 6717-6722, DOI 10.1021/es7022362.

(23) Lin, Z.; Zhen, Z.; Liang, Y.; Li, J.; Yang, J.; Zhong, L.; Zhao, L.; Li, Y.; Luo, C.; Ren, L.; et al. Changes in Atrazine Speciation and the Degradation Pathway in Red Soil during the Vermiremediation Process. J. Hazard. Mater. 2019, 364, 710-719, DOI 10.1016/j.jhazmat.2018.04.037.

(24) Corsi, S. R.; Mericas, D.; Bowman, G. T. Oxygen Demand of Aircraft and Airfield Pavement Deicers and Alternative Freezing Point Depressants. Water. Air. Soil Pollut. 2012, 223 (5), 2447-2461, DOI 10.1007/s11270-011-1036-x.

(25) Nzila, A. Current Status of the Degradation of Aliphatic and Aromatic Petroleum Hydrocarbons by Thermophilic Microbes and Future Perspectives. International Journal of Environmental Research and Public Health. 2018, DOI 10.3390/ijerph15122782.

(26) Cook, R. D. Cook's Distance. In International Encyclopedia of Statistical Science; 
Springer Berlin Heidelberg, 2011; pp 301-302, DOI 10.1007/978-3-642-04898-2_189.

\section{FOR TABLE OF CONTENTS ONLY}

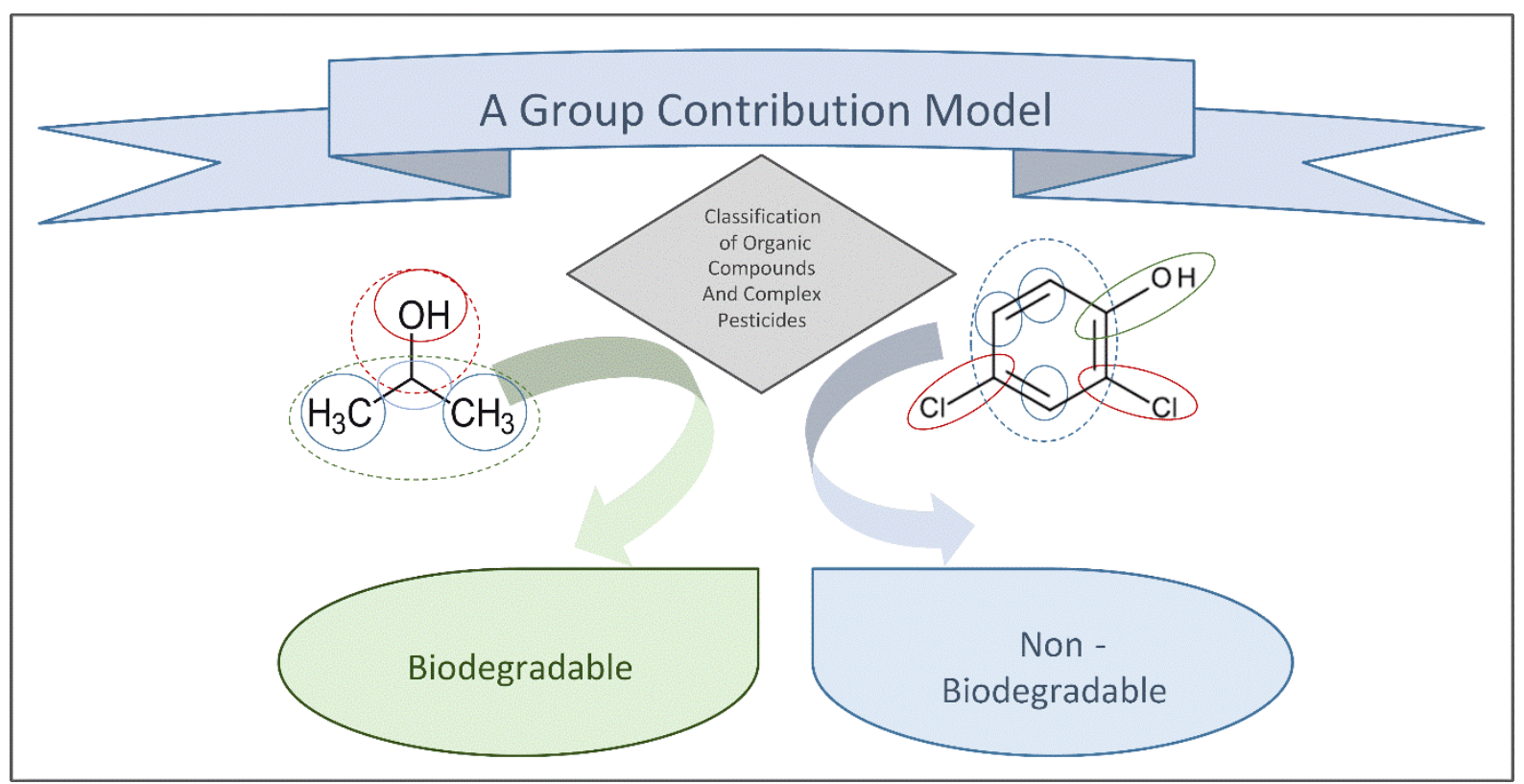

